\title{
Strengthened Relationships of Northwest China Wintertime Precipitation with ENSO and Midlatitude North Atlantic SST since the Mid-1990s
}

\author{
XiaOXUE Yin AND Lian-TONG ZHOU \\ Center for Monsoon System Research, Institute of Atmospheric Physics, Chinese Academy of Sciences, Beijing, China
}

(Manuscript received 20 June 2019, in final form 17 January 2020)

\begin{abstract}
The present study investigates the interdecadal changes in the relationship between El Niño-Southern Oscillation (ENSO) and midlatitude North Atlantic (MNA) sea surface temperature (SST) with northwest China (NWC) winter precipitation (WP) variability and the plausible causes. Results show that ENSO and MNA SST have weak correlations with NWC WP before the mid-1990s, whereas the connections are enhanced sharply afterward, with above (below) normal precipitation occuring when there are positive (negative) ENSO SST and negative (positive) MNA SST anomalies (SSTA). Remarkable differences are found in the atmospheric circulations. After the mid-1990s, there is a pronounced Pacific-North American-Eurasian (PNA-EU)-like pattern in the Northern Hemisphere, whereas an Arctic Oscillation-like pattern is found before the mid-1990s. The change in the relationships between NWC WP and SSTs is likely attributable to the enhanced connection between ENSO and MNA SST after the mid-1990s. It is found that ENSO and MNA SSTA can cause NWC WP variation independently through atmospheric teleconnections. In addition, significant precipitation anomalies also occur when concurrent but oppositely signed SSTs anomalies in the two regions are observed. The reinforced negative correlations between ENSO and MNA SST after the mid-1990s act in concert on NWC WP by exciting a PNA-EU-like pattern. This information would help us to better understand the physical processes of the teleconnections between NWC WP variability and the ENSO/MNA SST, in which the strength of the correlation between ENSO and MNA SST should be taken into account.
\end{abstract}

\section{Introduction}

With the increased winter snow and ice disasters, a great number of studies were carried out on wintertime precipitation variability in China (e.g., Zhou and $\mathrm{Wu}$ 2010; Wang and Feng 2011; Zhang et al. 2015). Winter precipitation anomalies in northwest China (NWC) could cause huge impacts on local society and economy development (Zhang et al. 2000). Thus, it is of great importance to explore the wintertime precipitation variations in NWC and their possible causes in order to improve the regional precipitation prediction and reduce the economic loss and casualties.

Our previous study (Yin and Zhou 2018) revealed that the first leading mode of winter precipitation variation in NWC demonstrates a uniform pattern at interannual scale. The local circulation that favors above-normal precipitation is a quasi-zonal pattern with positive height anomalies around Japan and negative anomalies over central Asia, consistent with the wet phase of the

\footnotetext{
Corresponding author: Lian-Tong Zhou, zlt@mail.iap.ac.cn
}

so-called dry circulation (Yang et al. 1984). Numerous studies have suggested that ENSO could exert influence on the East Asia monsoon as well as temperature and precipitation over China through the western North Pacific anticyclone (WNPAC; Zhang and Sumi 2002; Zhou et al. 2010; Zhou and Wu 2010). The El Niño event corresponds to a weaker than normal East Asia winter monsoon (EAWM; Zhang et al. 1996; Wang et al. 2000) and above-normal precipitation over NWC (Zhang et al. 2002). Wang et al. (2000) found that when the El Niño event reaches the mature phase in boreal winter, the WNPAC contains two separate centers including a tropical center over the Philippine Sea and a midlatitude center around the Kuroshio Extension. This midlatitude anticyclonic circulation could affect the eastern center of the dry circulation (Yang et al. 1984) over Japan. They also pointed out that the intensity and location of the midlatitude portion of the anomalous anticyclone displays large variability. In addition, many studies suggested that the sea surface temperature (SST) anomalies over the North Atlantic could also excite remarkable influences on Eurasian climate variation by 
inducing a zonal teleconnection pattern (e.g., Wallace and Gutzler 1981; Wu et al. 2011; Liu et al. 2014; Chen et al. 2016). This eastward-propagating wave train stems from the North Atlantic and spreads to East Asia, which could play a key role in the amplitude of the dry circulation and influence the climate variability over NWC (Wang and Zhang 2015; Zhou and Wu 2015).

However, the interrelationships between regional climate and large-scale climate variability are not stable from one decade to another (e.g., Wu et al. 2010; Cai et al. 2010; Zhou 2011; King et al. 2013; Hatzaki and Wu 2015; Chen and Wu 2017). The influences of ENSO on regional climate variation are unstable and could be modulated by many factors (e.g., Wu et al. 2010; Cai et al. 2010, 2012; King et al. 2013). Cai et al. (2010) found a breakdown of the relationships between Australian climate and ENSO teleconnection since the 1980 s, which caused a rainfall reduction in southeast Queensland after the 1980s. King et al. (2013) indicated that the asymmetry relationship between ENSO and extreme rainfall in eastern Australia has significant decadal variability that is dependent upon the phase of the interdecadal Pacific oscillation (IPO). Some studies suggested that the Pacific decadal oscillation (PDO), which is defined as the leading mode of SST anomalies (SSTA) in the North Pacific Ocean located to the north of $20^{\circ} \mathrm{N}$, is the key factor possibly modulating the ENSO-related WNPAC (Wang et al. 2008; Wang and He 2012). Wang et al. (2008) revealed that when the PDO is in the positive phase, the anomalous anticyclone related to the El Niño events is confined to the Philippine Sea. In contrast, when the PDO is in the negative phase, the anomalous anticyclone shifts northward and the strong southerly wind anomalies penetrate to higher latitudes, contributing to a robust connection between ENSO and East Asia climate variability. The connections between the North Atlantic SSTA and the climate variability over Eurasia are also unstable (Chen et al. 2015; Hatzaki and Wu 2015; Chen and Wu 2017). For instance, Hatzaki and Wu (2015) suggested that the North Atlantic SST had a close connection with the southeastern Europe winter precipitation in the mid-1960s to the mid-1980s, whereas the relation has weakened since the mid-1980s. Chen and $\mathrm{Wu}$ (2017) also found that there are interdecadal changes in the relationship between the North Atlantic tripole SSTA and spring surface air temperature over Eurasia in the early 1970s and the mid-1990s, owing to the changes in the atmospheric heating that is related to the mean state of the North Atlantic SST. These unstable linkages of the regional climate to ENSO or Atlantic SSTA could lead to low climate predictability. Thus, the long-term variation of the NWC winter precipitation (WP)-ENSO/Atlantic connections is important but has not been well recognized so far. In this study, we aim to investigate and understand the interdecadal changes in the relation of NWC WP with the SSTA in the tropical eastern Pacific and the North Atlantic.

Moreover, previous studies have revealed an interfered or a combined influence of the tropical Pacific and the North Atlantic SSTA on regional climate variability (e.g., Spence et al. 2004; Wu and Kirtman 2011). For example, Spence et al. (2004) argued that the combined effects of the tropical Pacific and the Atlantic SSTA on the Caribbean summer rainfall are complicated and important. The strongest rainfall response occurs when out-of-phase SSTA in the two regions are observed. Besides, previous studies found that ENSO could induce SSTA in the Atlantic area through atmospheric teleconnections (Wallace and Gutzler 1981; Enfield and Mayer 1997; Yin and Zhou 2019). For example, the Pacific-North American (PNA) teleconnection pattern (Enfield and Mayer 1997) is considered as one of the primary ways linking ENSO and the North Atlantic SSTA. Thus, ENSO may impact regional climate variations indirectly through the Atlantic variability (Giannini et al. 2000; Wu et al. 2011). Therefore, another issue to be addressed in this study is the relative contributions of the SSTA in the tropical Pacific and the North Atlantic on NWC WP variability, and it is interesting to explore whether there are multiple ways in which ENSO could induce precipitation anomalies in NWC.

The remainder of this paper is organized as follows. In section 2, we describe the dataset and the analysis method applied in this study. Section 3 addresses the interdecadal change in the relationships between NWC WP with the SSTA and the atmospheric circulations. Section 4 presents the individual and the combined impacts of ENSO and MNA SSTA by using a conditional composite analysis. In section 5, plausible reasons for the interdecadal change in the precipitation-SSTs relationships are investigated. A summary and discussion are given in section 6 .

\section{Data and methods}

The present study uses monthly mean precipitation data of 553 stations in China from 1961 to 2014, provided by the National Climate Center of the China Meteorological Administration, and the monthly mean precipitation reconstruction dataset over land (PREC/L) produced by the National Oceanic and Atmospheric Administration (NOAA) (Chen et al. 2002), which is available on a $0.5^{\circ} \times 0.5^{\circ}$ grid in longitude and latitude since January 1948. The SST dataset used in this study is the NOAA Extended Reconstruction SST, version 3 (Smith et al. 2008), which has a horizontal resolution of 
$2.0^{\circ} \times 2.0^{\circ}$ (latitude and longitude) and is available from 1854 to the present. This study also employs the monthly mean sea level pressure (SLP), geopotential heights, winds, and relative humidity at different pressure levels from the National Centers for Environmental Prediction-National Center for Atmospheric Research (NCEP-NCAR) reanalysis (Kalnay et al. 1996). These variables are available on a $2.5^{\circ} \times 2.5^{\circ}$ grid in longitude and latitude for the period from 1948 to present. In addition, the monthly mean surface shortwave and longwave radiation and surface latent and sensible heat fluxes from the NCEP-NCAR reanalysis are employed. The results are confirmed by the OAFlux data, with a resolution of T62, covering the period from 1958 to 2009. The notation for surface heat fluxes is positive (negative) for downward (upward) fluxes.

The wave activity flux (Takaya and Nakamura 2001) is used to describe the propagation of the stationary Rossby wave. It is a phase-independent flux and is parallel to the local group velocity of a stationary Rossby wave train in the Wentzel-Kramers-Brillouin (WKB) approximation. The horizontal wave activity flux is calculated according to the following equation:

$$
R_{\mathrm{wa}}=\frac{p}{2|\mathbf{U}|}\left\{\begin{array}{l}
U\left(v^{2}-\psi^{\prime} v_{x}^{\prime}\right)+V\left(-u^{\prime} v^{\prime}+\psi^{\prime} u_{x}^{\prime}\right) \\
U\left(-u^{\prime} v^{\prime}+\psi^{\prime} u_{x}^{\prime}\right)+V\left(u^{\prime 2}+\psi^{\prime} u_{y}^{\prime}\right)
\end{array},\right.
$$

where $\mathbf{U}=(U, V),\left(u^{\prime}, v^{\prime}\right), \psi^{\prime}$, and $T^{\prime}$ are the climatological zonal and meridional wind velocity, the perturbation of geostrophic wind, streamfunction, and air temperature. Also, $R_{a}, H_{0}, f_{0}, N$, and $p$ are the dry air gas constant, atmosphere scale height, Coriolis parameter at $45^{\circ} \mathrm{N}$, buoyancy frequency, and pressure, respectively. The subscripts $x$ and $y$ indicate the partial derivatives in the zonal and meridional directions, separately.

This study constructs the wintertime mean by averaging the data over November, December, January, February, and March (NDJFM). The NWC WP is defined as the leading mode of NDJFM precipitation of the 130 stations (dots in Fig. 1a) located to the west of $110^{\circ} \mathrm{E}$ and to the north of $35^{\circ} \mathrm{N}$ in China obtained using the empirical orthogonal function (EOF) method, following Yin and Zhou (2018). The Niño-3.4 SST $\left(5^{\circ} \mathrm{S}-5^{\circ} \mathrm{N}, 170^{\circ}-\right.$ $120^{\circ} \mathrm{W}$ ) is used as an index for ENSO. The MNA SST index is constructed as the SSTA averaged over $30^{\circ}-50^{\circ} \mathrm{N}$, $60^{\circ}-30^{\circ} \mathrm{W}$ to describe the SST variation over the midlatitudes North Atlantic. The Arctic Oscillation (AO) index is defined as the first leading EOF mode of SLP anomalies over the Northern Hemisphere (NH) extratropics $\left(20^{\circ}-90^{\circ} \mathrm{N}\right)$ (Thompson and Wallace 2000$)$. The anomalies are constructed by removing the climatological mean based on the period 1961-2013. As the analysis in this study focuses on the interannual-scale variations of (a) $\mathrm{EOF} 1$

$25.6 \%$
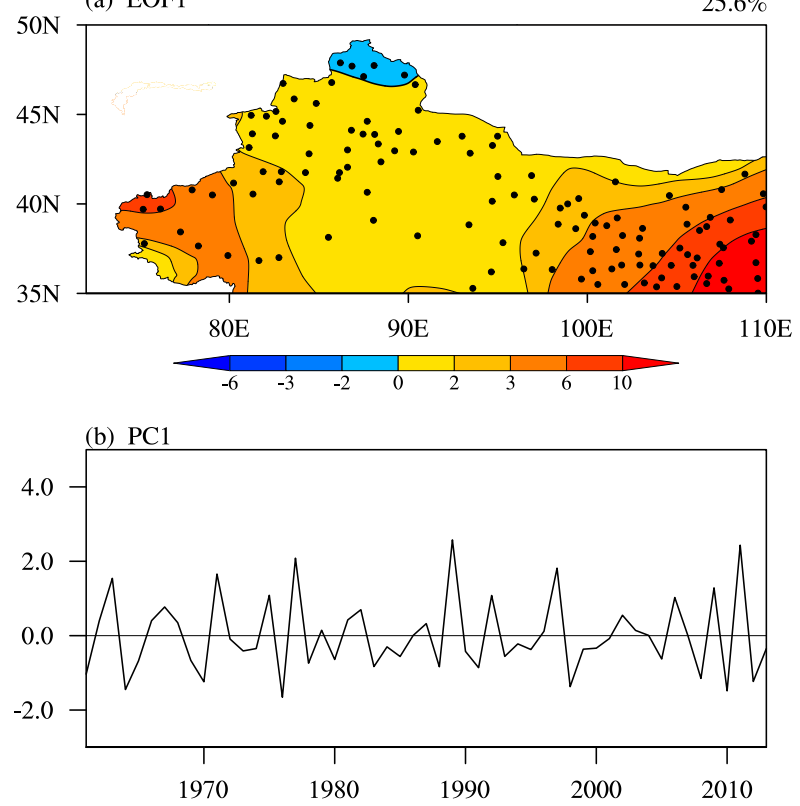

FIG. 1. EOF1 of the interannual wintertime precipitation variations in NWC for 1961-2013. (a) Regression maps on the normalized principal component (unit: $\mathrm{mm}$ ). (b) The normalized principal component (i.e., the NWC WPI). The dots in (a) demonstrate the distribution of the 130 stations in NWC.

9 years, longer time scale variations have been removed using a Lanczos filter (Duchon 1979). The Fisher's $r-z$ transformation is applied to estimate the significance of the difference between two correlation coefficients (CCs; Fisher 1921). The statistical significance of the composite anomalies is evaluated by comparing the magnitude of the composite anomalies to the standard deviation of the individual anomalies with respect to the composite anomalies in the same group of cases ( $\mathrm{Wu}$ and Kirtman 2011).

\section{Interdecadal change in the relationships between NWC WP and SSTs}

In this section, we investigate the interdecadal change in the relationships between NWC WP with ENSO and the MNA SSTA. This is followed by a comparison of the SSTA evolution before and after the mid-1990s. Then the contrast of the associated atmospheric circulations is inspected to understand the possible processes in which the SST forcing exerts its influences on NWC WP anomaly.

Figure 1 demonstrates the first EOF mode of winter precipitation in NWC. It explains about $25.6 \%$ of the total variance of winter precipitation and demonstrates an in-phase pattern (Fig. 1a), with maximum values located in western Xinjiang and eastern NWC and the 
(a) SST

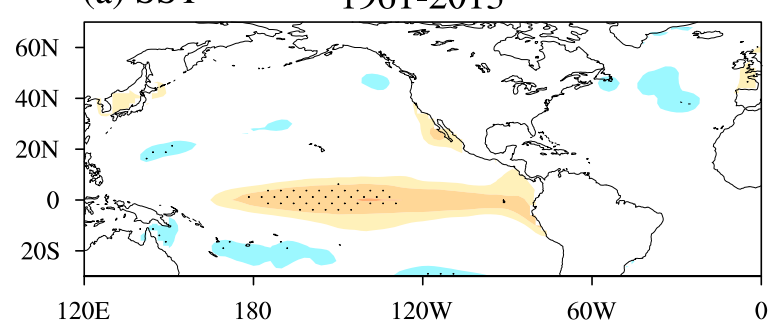

(b) SST

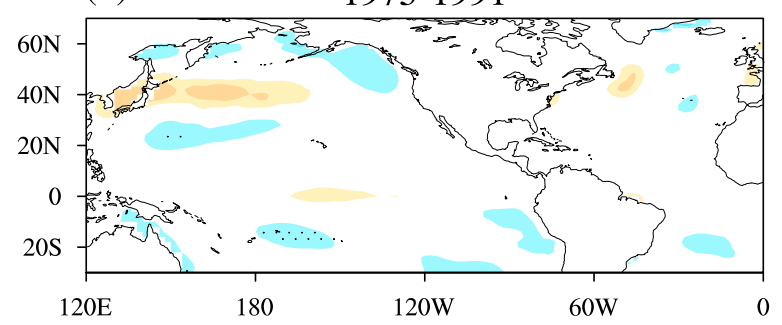

(c) SST

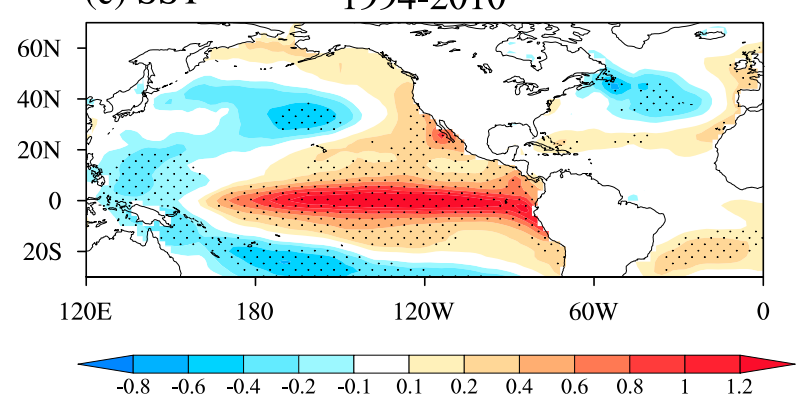

FIG. 2. SST anomalies $\left({ }^{\circ} \mathrm{C}\right)$ in winter obtained by regression on NWC WPI for (a) 1961-2013, (b) 1975-91, and (c) 1994-2010. Shading interval is $0.2^{\circ} \mathrm{C}\left(0.1^{\circ} \mathrm{C}\right)$ for magnitudes larger (less) than $0.2^{\circ} \mathrm{C}\left(0.2^{\circ} \mathrm{C}\right)$. The dotted regions indicate the $95 \%$ confidence level, based on the Student's $t$ test.

minimal values between the above two regions. The normalized principal component (Fig. 1b) is defined as the NWC WP index (WPI), which will be used in the following study.

Figure 2 shows the winter SSTA obtained by regression on the NWC WPI. For period 1961-2013, positive SSTA appear in the tropical eastern-central Pacific (Fig. 2a), indicating a positive connection between NWC WP and the El Niño events, consistent with our previous study (Yin and Zhou 2018). However, note that the intensity of the SSTA is not very strong, which may imply an interdecadal change in the relationship (Figs. 2b,c). In 1975-91, virtually no obvious signals can be found in the SSTA field (Fig. 2b). To the contrary, in 1994-2010, significant positive SSTA are observed in the equatorial eastern Pacific and negative SSTA are seen in the western Pacific (Fig. 2c). Thus, it indicates an enhanced connection between NWC WP and ENSO events in the latter period. Besides the positive SSTA in

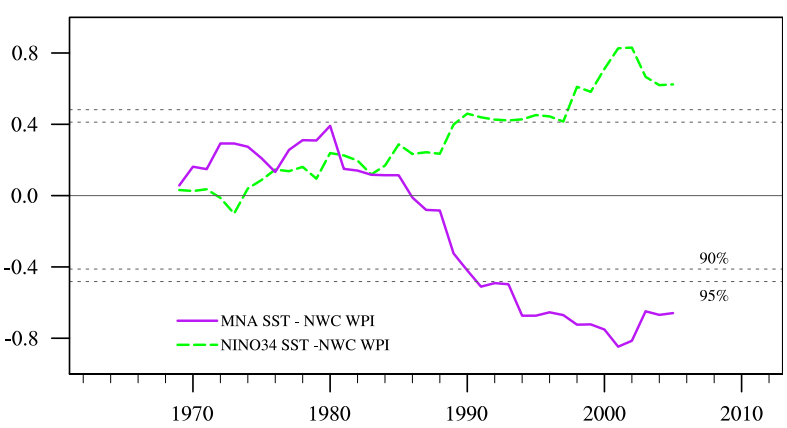

FIG. 3. Moving correlation coefficients of winter MNA SST (purple solid line) and Niño-3.4 SST (green dashed line) with NWC WPI using a 17-yr window. The correlation coefficient is shown at the center year of the 17 -yr window. The dashed gray lines indicate the $90 \%$ and $95 \%$ confidence levels, based on the Student's $t$ test.

the tropical eastern Pacific, pronounced negative SSTA are found in the midlatitude North Atlantic (MNA) during 1994-2010 (Fig. 2c). The SSTA are quite weak over North Atlantic in 1975-91. Thus, it may also imply an enhanced connection between NWC WP and the MNA SSTA.

The selection of the above two subperiods is based on a 17-yr sliding correlation of SSTA in the Niño-3.4 region and the MNA region with NWC WPI (Fig. 3). Apparently, weak positive CC is seen during the 1970s to the early 1990s for both Niño-3.4 and MNA SST. The CCs become statistically positive for Niño-3.4 SST and negative for MNA SST after the early 1990s. Years 1983 and 2002 are approximately the center years when the two 17-yr sliding correlations are at their lowest value and highest value. The CCs in 197591 are 0.12 for both Niño-3.4 SST and MNA SST, whereas the CCs in 1994-2010 become 0.83 for Niño3.4 SST and -0.81 for MNA SST, respectively. The CCs between these two periods are statistically different at $95 \%$ confidence level, according to a test based on the Fisher's $r$-to- $z$ transform (Fisher 1921). Thus, we will choose 1975-91 (hereafter P1) and 1994-2010 (hereafter P2) as two subperiods in the following analysis. Similar results are gained by using different lengths of window for the sliding correlation. Table 1 further presents the statistical result of the frequency of positive and negative relationships between NWC WP anomalies and the ESNO/MNA SSTA selected when the anomalies are large than 0.5 standard deviation. Use of a different criterion leads to changes in the number of years selected, but does not alter the statistical relationship discussed below. For MNA SST and NWC WPI, there are 7 same-sign years and 7 opposite-sign years during P1, and 8 opposite-sign years and zero same-sign years for P2. This demonstrates an enhanced negative connection 
TABLE 1. Number of cases when the midlatitude North Atlantic (MNA; $\left.30^{\circ}-50^{\circ} \mathrm{N}, 60^{\circ}-30^{\circ} \mathrm{W}\right) \mathrm{SST}$ anomalies and the Niño-3.4 $\left(5^{\circ} \mathrm{S}-\right.$ $\left.5^{\circ} \mathrm{N}, 170^{\circ}-90^{\circ} \mathrm{W}\right) \mathrm{SST}$ anomalies have the same sign or opposite sign as NWC winter precipitation index during 1961-93 and 1994-2013.

\begin{tabular}{lcccccc}
\hline \hline & \multicolumn{2}{c}{ MNA SST } & & \multicolumn{2}{c}{ Niño-3.4 SST } \\
\cline { 2 - 3 } \cline { 5 - 6 } \cline { 5 - 6 } & $1961-93$ & $1994-2013$ & & $1961-93$ & $1994-2013$ \\
\hline Same sign & 7 & 0 & & 8 & 7 \\
Opposite sign & 7 & 8 & & 6 & 0
\end{tabular}

between the MNA SST and NWC WP. For the Niño3.4 SST and NWC WPI, there are 8 same-sign years and 6 opposite-sign years in P1, and 7 same-sign years with no opposite-sign years for $\mathrm{P} 2$, indicating a higher

(a) SON

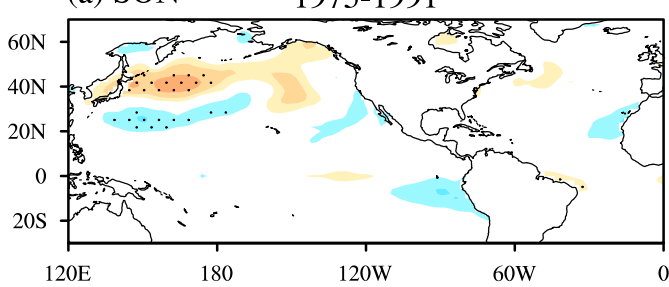

(b) NDJ

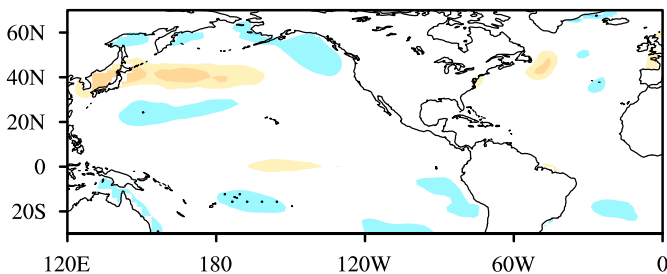

(c) JFM

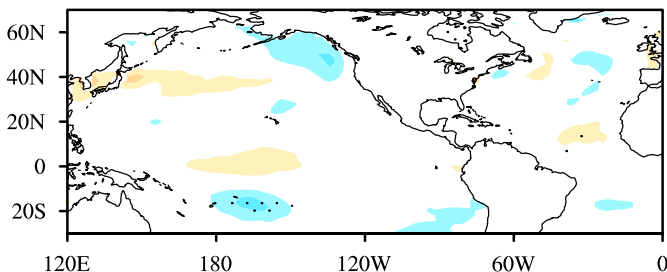

(d) MAM

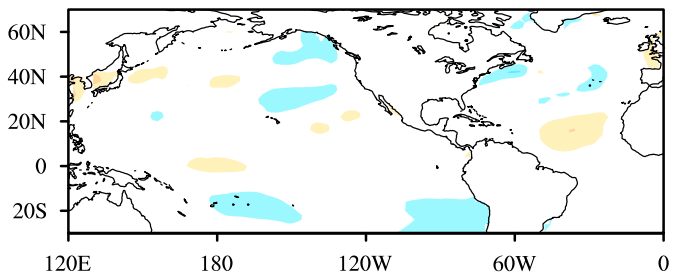

positive relation between the Niño-3.4 SST and NWC WP.

Figure 4 further gives the seasonal SSTA obtained by regression onto the WPI for P1 and P2. The SSTA display pronounced differences in the two subperiods. In P1 (Figs. 4a-d), virtually no SSTA can be observed in both the equatorial Pacific and the North Atlantic regions. In $\mathrm{P} 2$ (Figs. $4 \mathrm{e}-\mathrm{h}$ ), conspicuous positive SSTA are seen in the equatorial eastern Pacific and negative SSTA are found in the western Pacific. This El Niño-like SSTA pattern takes place in the preceding seasons, peaks in winter, and decreases in spring. In addition, significant negative SSTA dominate the midlatitudes North Atlantic (Figs. 4e-g). These SSTA develop in the preceding autumn (Fig. 4e), increase and peak in winter
1994-2010

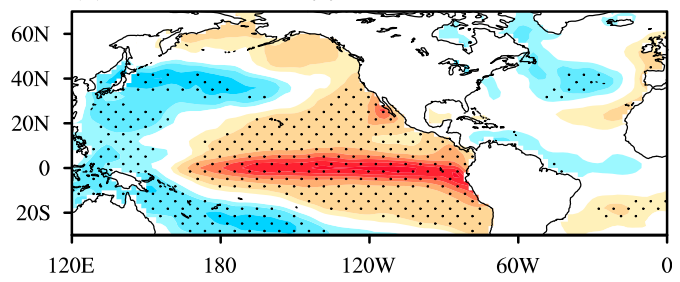

(f) NDJ

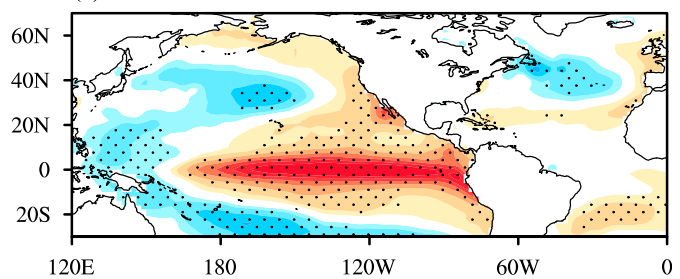

(g) JFM

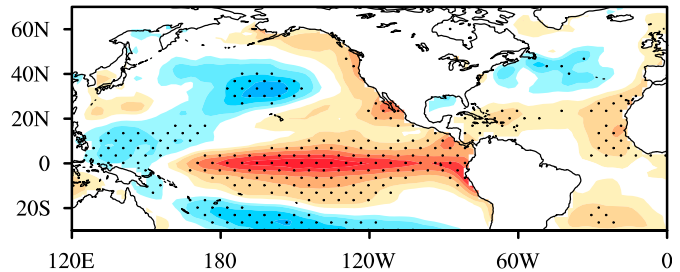

(h) MAM

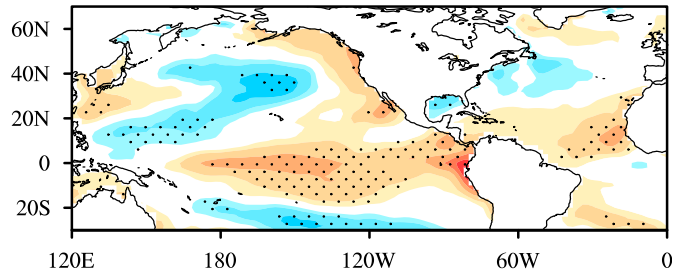

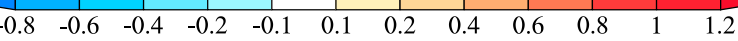

FIG. 4. SST anomalies $\left({ }^{\circ} \mathrm{C}\right)$ in (a),(e) SON, (b),(f) NDJ, (c),(g) JFM, and (d),(h) MAM obtained by regression on NWC WPI for (left) 1975-91 and (right) 1994-2010. Shading interval is $0.2^{\circ} \mathrm{C}\left(0.1^{\circ} \mathrm{C}\right)$ for magnitudes larger (less) than $0.2^{\circ} \mathrm{C}\left(0.2^{\circ} \mathrm{C}\right)$. The dotted regions indicate the $95 \%$ confidence level, based on the Student's $t$ test. 


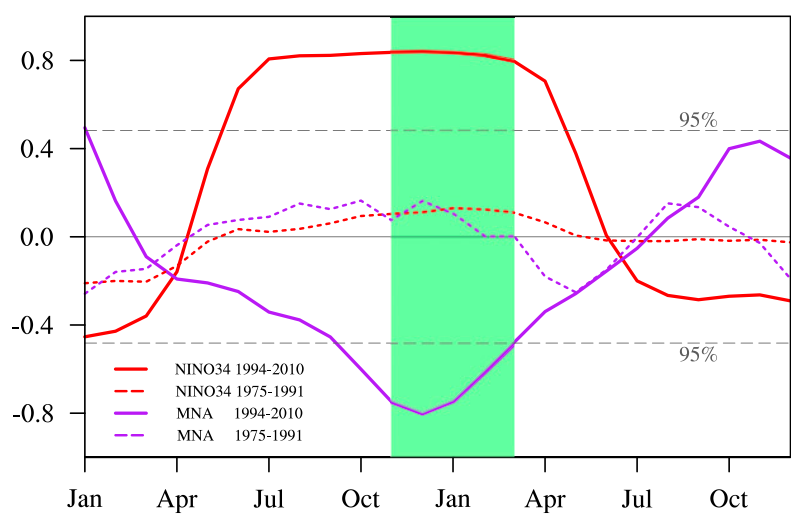

FIG. 5. Lag-lead correlations of monthly-mean MNA SST (purple curve) and Niño-3.4 SST (red curve) with NWC WPI for period 197591 (dashed curve) and 1994-2010 (solid curve). The dashed gray lines indicate the $95 \%$ confidence level, based on the Student's $t$ test.

(Fig. 4f) and weaken in the ensuing spring (Figs. 4g,h). Besides, in January-March (JFM) and March-May (MAM) (Figs. 4g,h), a positive SST anomaly develops in the tropical North Atlantic, consistent with previous studies that argued for a close connection between ENSO and the postspring tropical North Atlantic SSTA (e.g., Saravanan and Chang 2000; Giannini et al. 2001; Huang et al. 2002). Therefore, the evolution of the SSTA demonstrated above verifies the stronger connections between NWC WPI with the Niño-3.4 and MNA SST in P2. This can be detected more clearly in Fig. 5. It presents the lag-lead CCs of monthly-mean Niño-3.4 and MNA SST with WPI for both P1 and P2. Distinctly, the lag-lead CCs are rather weak in P1 and become quite high in $\mathrm{P} 2$ with the CCs up to 0.8 before winter.

Figures 6-8 show the atmospheric circulation anomalies obtained by regression on the NWC WPI in different periods. During P1, the circulation anomalies are confined to the high latitudes in the NH. The SLP anomalies feature an AO-like pattern (Fig. 6a), with negative SLP anomalies locating in the polar region and positive anomalies lying in the North Pacific and the North Atlantic (though weak). The correlation coefficient between NWC WPI and the AO index is 0.41 in $\mathrm{P} 1$, significant at the $90 \%$ confident level. This pattern can also be observed at high level (Fig. 6b). The positive height anomalies over the North Pacific extend to Japan and cause significant southeasterly wind anomalies to the eastern boundary of NWC (Fig. 6c), which could bring water vapor (vectors; Fig. 6d) and induce precipitation anomalies in NWC. To the contrary, the circulation anomaly exhibits a circumglobal wave train pattern over the middle-to-high latitudes in the $\mathrm{NH}$ for P2 (Figs. 6e-g), including a remarkable Eurasian (EU) pattern over Eurasia and a PNA-like pattern from the North Pacific to North America (Wallace and Gutzler 1981), which will be referred to as the PNA-EU-like pattern. These zonal wave-3 features can also be detected at $200 \mathrm{hPa}$ (not shown), indicating a quasi-barotropic structure. The positive height anomalies occupy North America, North Africa, and Japan, and the negative anomalies are discernible over the North Pacific, the North Atlantic, and large areas over the Ural region (shading; Fig. 6f). The negative and positive height anomalies over the Ural region and Japan give rise to the anomalous southeasterly and southwesterly wind to the east and west borders of NWC (Fig. 6g), and these wind anomalies converge over NWC with warm and moist air (Fig. 6h), which may favor above-normal precipitation. The wave activity flux at $500 \mathrm{hPa}$ also shows a hemisphere-wide propagation characteristic (vectors; Fig. 6f). The 250-hPa Rossby wave sources [defined as $-\nabla \cdot\left(v_{\chi} \zeta\right)$ by Sardeshmukh and Hoskins (1988)] are mainly located over the North Pacific, northwest coast of North America, eastern Canada, southwestern United States, eastern Atlantic, North Africa, and East Asia (Fig. 7b), basically consistent with the geopotential height anomalies (Fig. 6f). The positive wave source anomalies over the North Pacific (Fig. 7b) correspond to the cyclonic anomalies over the eastern North Pacific (Fig. 6f), which propagate eastward and probably form the PNA-like wave train (Simmons et al. 1983). Previous work suggested that the PNA teleconnection can be forced by the SSTA in the equatorial eastern-central Pacific and link the climate variability in North America and SSTA in the North Atlantic with ENSO events (Horel and Wallace 1981; Enfield and Mayer 1997; Giannini et al. 2000). The anomalous wave source to the eastern Canada (Fig. 7b) corresponds to the cyclonic anomalies over the North Atlantic (Fig. 6f), which generates a wave train propagating downward and may generate the EU-like wave train over Eurasia. The continental wave train extends from the North Atlantic and spreads eastward to western Europe, and then it turns northeastward to central Eurasia, and finally propagates southeastward to East Asia. The EU teleconnection can persist from November to March though the wave activity weakens in the early spring (not shown). Previous work suggested that a negative phase of EU favors above normal precipitation over East Asia and central Asia (Liu et al. 2014; Wang and Zhang 2015), and it can be driven by external forcing factors such as the SSTA in the North Atlantic region (Nakamura et al. 1987; Gambo et al. 1987; Liu et al. 2014; Chen et al. 2018). Given the significant negative SSTA over the midlatitudes North Atlantic (Fig. 2c), it implies that the MNA SSTA forcing may play a key role in NWC precipitation variability by 
(a) SLP

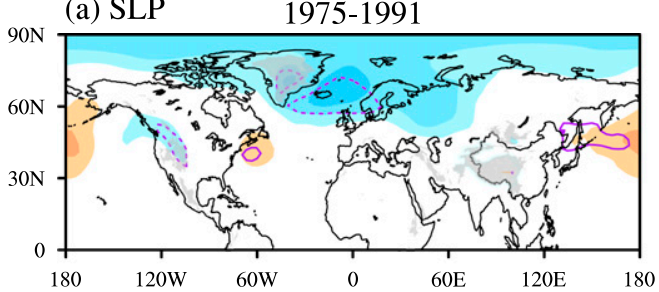

(b) Z500

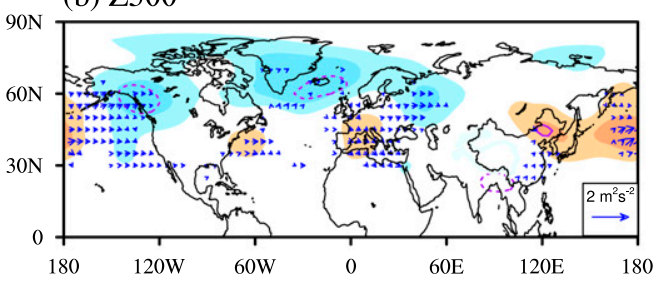

(c) 850 wind

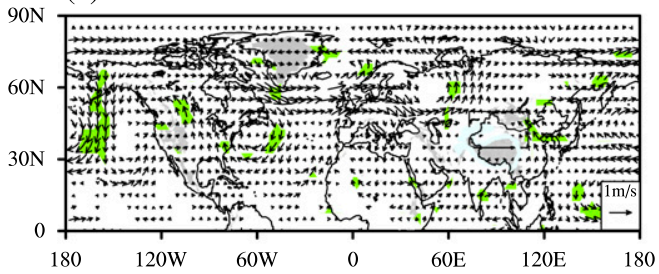

(d) WVF

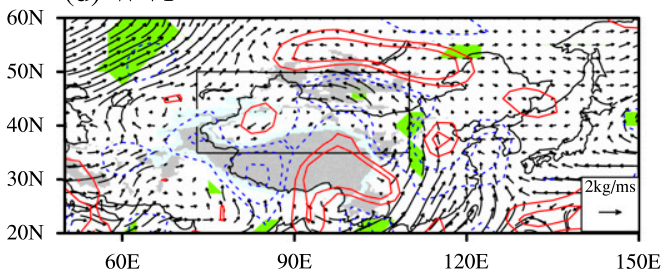

(e) SLP

1994-2010

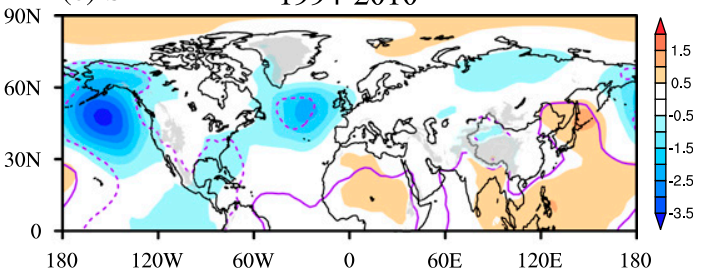

(f) Z500

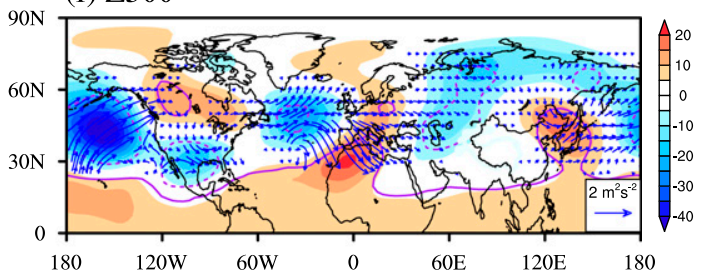

(g) 850 wind

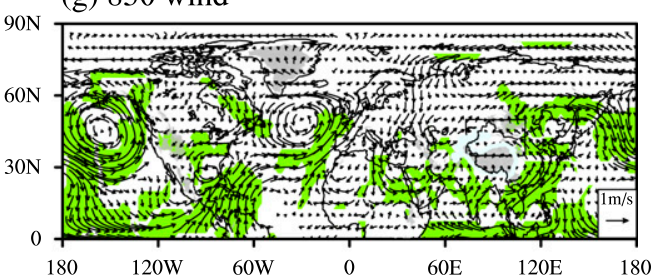

(h) WVF

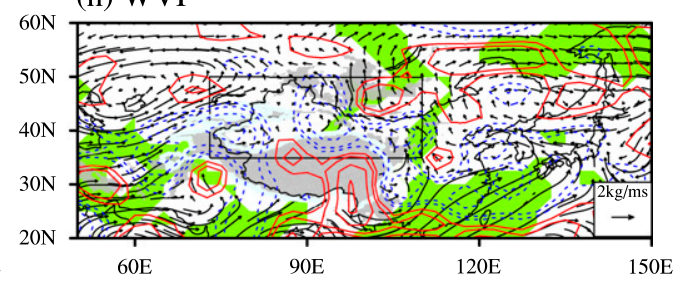

FIG. 6. Anomalies of winter (a),(e) surface level pressure (SLP; hPa), (b),(f) 500-hPa geopotential height (shading; gpm) and horizontal wave activity flux (vectors; $\left.\mathrm{m}^{2} \mathrm{~s}^{-2}\right),(\mathrm{c}),(\mathrm{g})$ 850-hPa winds $\left(\mathrm{m} \mathrm{s}^{-1}\right)$, and (d), (h) lowlevel (1000-700 hPa) integrated water vapor flux (WVF; vectors, $\mathrm{kg} \mathrm{m}^{-1} \mathrm{~s}^{-1}$ ) and the divergence of the 850-hPa wind (contours; interval: $2 \times 10^{-6} \mathrm{~s}^{-1}$ ) obtained by regression on NWC WPI for (left) 1975-91 and (right) 19942010. The purple contours and the green shading indicate the $95 \%$ confidence level, based on the Student's $t$ test. The wave activity flux (wind) with magnitude less than $0.12 \mathrm{~m}^{2} \mathrm{~s}^{-2}\left(0.03 \mathrm{~m} \mathrm{~s}^{-1}\right)$ are suppressed. Positive (negative) values are indicated by solid red (dashed blue) contours with the zero contour omitted in (d) and (h). The Chinese region in the rectangular box in (c), (d), (g), and (h) indicates the location of NWC. The gray shadings mark terrain higher than $1500 \mathrm{~m}$.

modulating the EU pattern. This will be discussed in section 4.

Moreover, the anomalous midlatitudes anticyclone around Japan (Fig. 6f) resembles the extratropical portion of the WNPAC that is associated with the El Niño events identified by Wang et al. (2000), although the anomalous center is shifted more westward. This anticyclonic circulation contributes to the southeasterly wind anomalies to its southwest margin, which could bring warm and moist air to NWC (vectors; Fig. 6h). Figure 8 further gives the anomalous velocity potential and divergent winds obtained by regression on the NWC WPI. At $850 \mathrm{hPa}$ (Fig. 8d), there is a dipole pattern with a divergence center over the eastern
Philippine Sea and a convergence center above the equatorial eastern Pacific, a feature often seen during warm ENSO events (Klein et al. 1999). The divergent winds flow from the Philippine Sea to the equatorial eastern Pacific and the NWC region and converge there. Another minor divergence center is discernible to the east of Japan, coincident with the enhanced SLP anomalies (Fig. 6e) and the anomalous midlatitude anticyclone (Fig. 6g). The upper-tropospheric velocity potential and divergent winds (Fig. 8c) are opposite to that at $850 \mathrm{hPa}$. In P1, there are very weak anomalies in these fields (Figs. 8a,b). Previous studies suggested that the intensity and location of the midlatitude portion of the WNPAC display large variability from event to event (e.g., 
(a) RWS

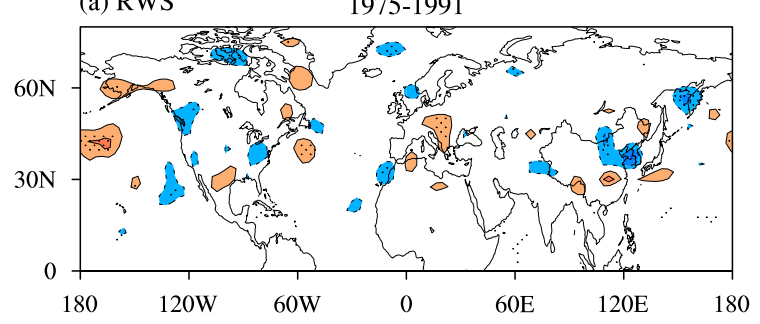

(b) RWS

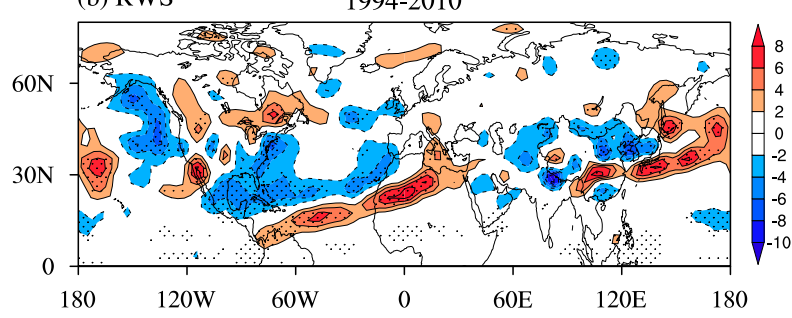

FIG. 7. Anomalies of winter $250-\mathrm{hPa}$ Rossby wave source $\left(10^{-10} \mathrm{~s}^{-2}\right)$ obtained by regression on NWC WPI for (a) 1975-91 and (b) 1994-2010. Dotted regions indicate the 95\% confidence level, based on the Student's $t$ test.

Wang et al. 2000). Thus, it may indicate an enhanced connection between ENSO and the midlatitudes anticyclone in the second period, which could result in a strengthened relation between ENSO and NWC WP.

The above results indicate that winter precipitation variability in NWC is mainly related to the AO-like pattern during 1975-91, while it is primarily affected by a PNA-EU-like teleconnection over the mid-to-high latitudes in the NH during 1994-2010. As discussed above, this circumglobal pattern is likely to be forced by the combined effects of the Niño-3.4 and MNA SST. Thus, these two SSTAs appear to act in concert with one another on NWC winter precipitation anomaly in $\mathrm{P} 2$. We will verify their combined effects as well as their respective influences on the atmospheric circulation anomalies and NWC WP variations in the following section using canonical composite analysis.

\section{Individual and combined influences of SSTs}

Before we explore the interdecadal change in the relationships between the MNA and Niño-3.4 SSTA with NWC WP, we investigate the respective and joint effects of MNA and Niño-3.4 SSTA on the atmospheric circulations and NWC WP by preforming a composite analysis, which could help us understand the reason for the interdecadal shift of the NWC WP-ENSO/MNS SST relationships discussed later.

The detailed statistical relations of NWC WPI with the two SSTA are examined and shown in Table 2, based on a standard deviation of 0.5 . Seven cases are found when the MNA index is opposite to NWC WP anomalies and the Niño-3.4 index is near normal or opposite to the WPI during 1961-2013. In these years (hereafter (a) $200 \mathrm{hPa}$

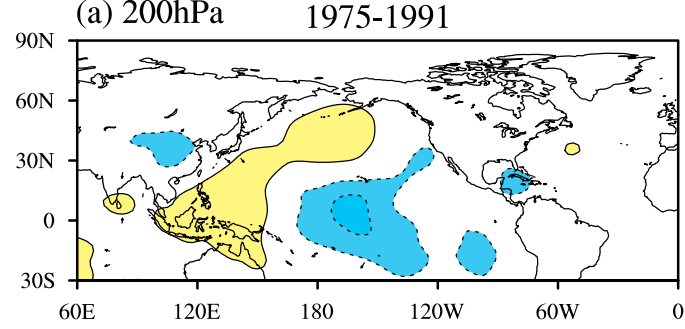

(b) $850 \mathrm{hPa}$

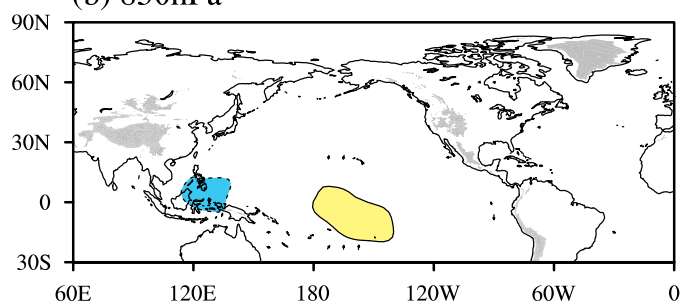

(c) $200 \mathrm{hPa}$

1994-2010

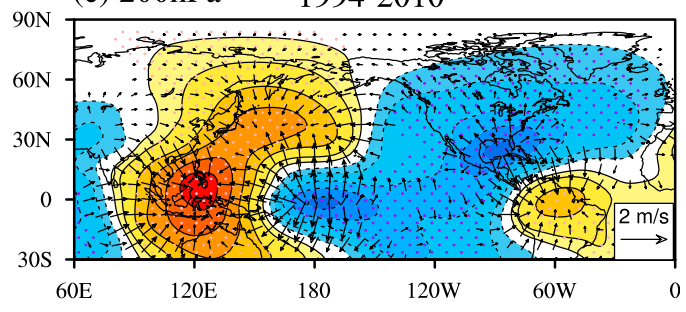

(d) $850 \mathrm{hPa}$

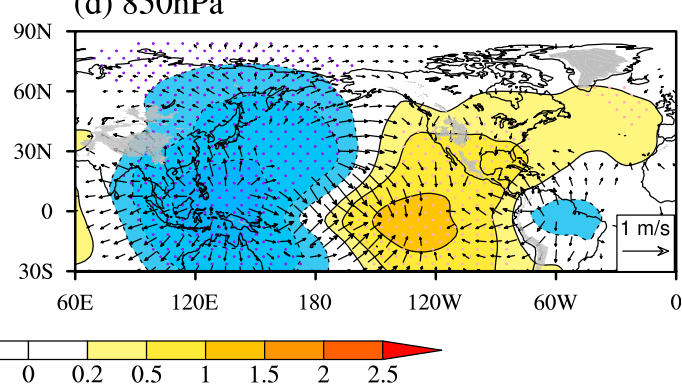

FIG. 8. Anomalies of winter velocity potential (shading; $10^{6} \mathrm{~m}^{2} \mathrm{~s}^{-1}$ ) at (a),(c) $200 \mathrm{hPa}$ and (b),(d) $850 \mathrm{hPa}$ with the corresponding divergent winds (vectors; $\mathrm{m} \mathrm{s}^{-1}$ ) obtained by regression on NWC WPI for (left) 1975-91 and (right) 1994-2010. Dotted regions indicate the 95\% confidence level for velocity potential, based on the Student's $t$ test. Statistically significant areas at $95 \%$ confidence level are gridded for divergent winds. The gray shadings mark the terrain higher than $1500 \mathrm{~m}$. 
TABLE 2. Cases when only the Niño-3.4 SST anomalies, the MNA SST anomalies, and both the MNA and Niño-3.4 SST anomalies contribute positively to wintertime precipitation variability over NWC during 1961-2013.

\begin{tabular}{ccc}
\hline \hline MNA-SST only & ENSO-SST only & Both-SST \\
\hline $1961,1969,1971,1989,1991,2008,2012$ & $1964,1970,1977,1980,1982,1988,2010$ & $1963,1983,1997,1998,2002,2005$, \\
& & 2006,2009 \\
\hline
\end{tabular}

aliased as MNA-SST only cases), the MNA SSTA may contribute to NWC WP anomalies independently. For the same period, there are 7 years in which the Niño-3.4 index has the same sign as WPI and the MNA index is near normal or of the same sign as the WPI. In these cases (hereafter aliased as ENSO-SST only cases), the NWC WP anomalies may be attributed to the Niño-3.4 SSTA individually. Note that there are equal numbers of MNA-SST and Niño-3.4-SST only cases in the research period; their impacts on the precipitation variations seem comparable. Eight years are recorded when the MNA index is opposite to the precipitation anomalies and the Niño-3.4 index has the same sign with WPI. In all these years (hereafter aliased as Both-SST cases), the MNA and Niño-3.4 SSTA could constructively contribute to NWC WP anomalies. In the following, we will calculate the composited results for the above three types of cases, including the anomalous SST, atmospheric circulation and precipitation in boreal winter. The anomalies are multiplied by -1 when the NWC WPI is negative; thus, the following results correspond to the cases when the NWC WP anomaly is above normal.

Figure 9 demonstrates the composite SSTA based on the above three types. The spatial distributions of the SSTA are shown at the simultaneous time as NWC WP and the temporal evolution is displayed as consecutive 3-month mean from the preceding JAS (JulySeptember) to AMJ (April-June). In the MNA-SST only cases, negative SSTA are seen in the midlatitude North Atlantic, and the SSTA are weak in the tropical Pacific (Fig. 9a). In this case, the MNA SSTA form in the early winter and vanish in the following spring (Fig. 9b). In the ENSO-SST only cases, large positive SSTA are observed in the tropical eastern-central Pacific while the SSTA signal in the MNA is quite weak (Fig. 9c). The temporal evolution of the Niño-3.4 SST implies a mature phase of El Niño event in winter, which develops in the preceding summer and decreases in spring (Fig. 9d). In the Both-SST cases, there are noticeable negative SSTA in the MNA area and positive SSTA in the Niño-3.4 region (Fig. 9e). In this case, the magnitude of the negative MNA SSTA is much larger compared with those in Fig. 9a, and they last from preceding autumn to the ensuing spring (Fig. 9f). This may be due to the external forcing from the Niño-3.4 SSTA, which lead the MNA SSTA by months (Fig. 9f), as previous studies suggested that ENSO could induce SSTA in the North Atlantic through atmospheric teleconnection (e.g., Enfield and Mayer 1997; Giannini et al. 2000; Alexander et al. 2002).

\section{a. Individual influence of MNA SST and Niño-3.4 SST}

Figure 10 shows the composite anomalies of $500-\mathrm{hPa}$ geopotential height and wave activity fluxes, $850-\mathrm{hPa}$ winds, and land precipitation in winter for cases when the Niño-3. 4 SSTA are near normal and the MNA SST may play the key role on NWC WP variability. The following analysis is related to the negative MNA SSTA, and the results for the positive MNA SSTA are opposite. A negative height anomalous center is observed over the North Atlantic (shading; Fig. 10a), which lies to the north of the negative MNA SSTA (Fig. 9a). Previous studies suggested that the storm track activity plays an important role in the atmospheric response to midlatitude SSTA (Trenberth and Hurrell 1994; Peng and Whitaker 1999; Kushnir et al. 2002). Also, Liu et al. (2014) found that the anomalous center of the EU pattern located over the North Atlantic region is primarily forced by the storm track activities. To investigate the storm track activities for the MNA-only cases, the composite of the eddy growth rate and the storm track are calculated (Fig. 11). The 700-hPa eddy growth rate [Fig. 11a; defined as $\sigma=0.3125(f / N)(d u / d z)$ by Lindzen and Farrell (1980)] shows that the baroclinicity is reduced (enhanced) to the north (south) of the cold MNA SSTA (Fig. 9a). Accordingly, the 300-hPa storm track (Fig. 11b), estimated by the standard deviation of the 2-8-day bandpass filtered 300-hPa geopotential height (Blackmon et al. 1977), is weakened over southeast Greenland and strengthened over the central North Atlantic. The weakened storm activities in southeast Greenland transport a negative geopotential height tendency to the south, and the enhanced storm activities over the central North Atlantic transport a positive geopotential height tendency to the north. Such a distribution of storm activities then facilitates the negative geopotential height tendency (Lau and Holopainen 1984) over the North Atlantic (shading; Fig. 10a). Downstream, there is a zonally distributed circulation pattern over Eurasia, with two positive centers occupying western Europe and northeastern Asia and a negative center lying near the Ural Mountains. This 
(a) MNA-SST only

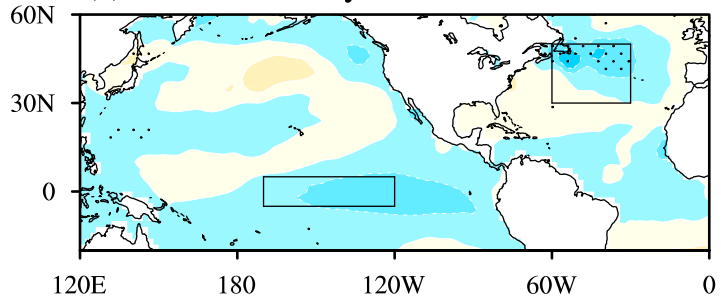

(c) ENSO-SST only

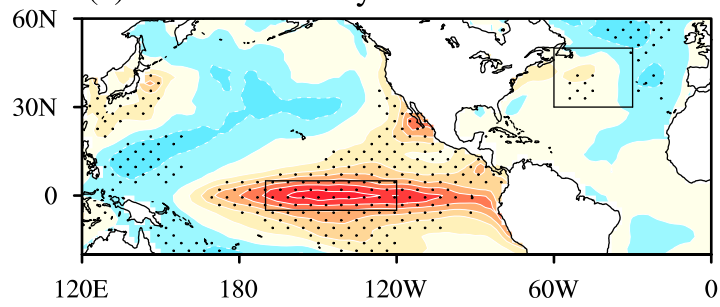

(e) Both-SST

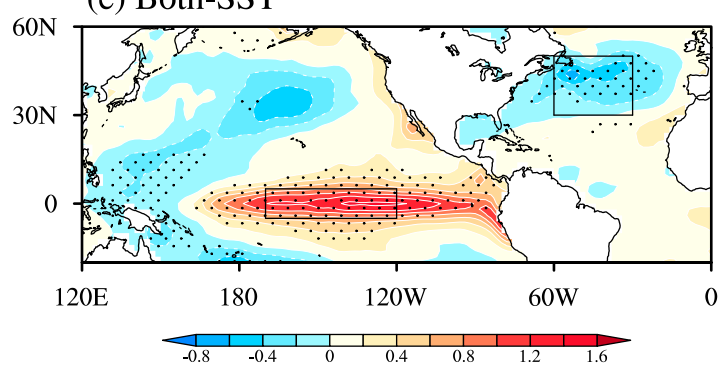

(b) MNA-SST only

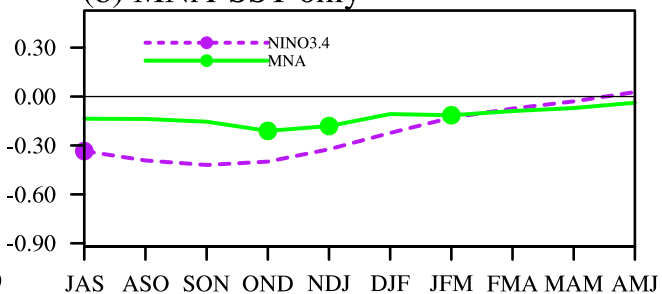

(d) ENSO-SST only

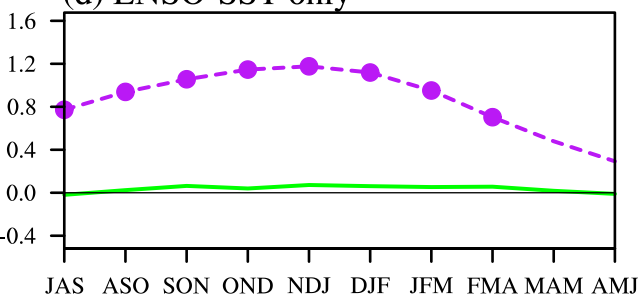

(f) Both-SST

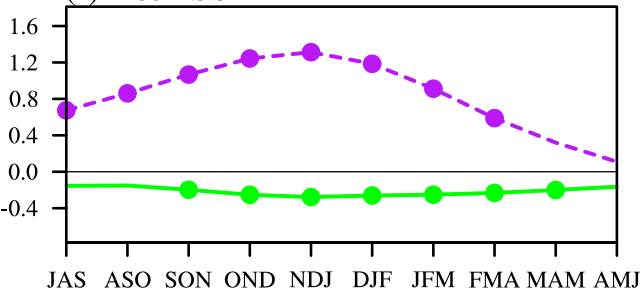

FIG. 9. (left) Spatial distribution of winter SST anomalies and (right) the evolution of the 3-month mean MNA and Niño-3.4 indices for different cases: (a),(b) MNA-SST only, (c),(d) ENSO-SST only, and (e),(f) Both-SST $\left({ }^{\circ} \mathrm{C}\right)$. Dots in (a),(c),(e) and marks in (b),(d),(f) denote that the magnitude of composite anomalies is large than one standard deviation of the individual anomalies with respect to the composite anomalies. Boxes in (a), (c), and (e) indicate the regions of Niño-3.4 SST and MNA SST.

circulation pattern is similar to the negative phase of the EU teleconnection (Wallace and Gutzler 1981). Previous work found that the North Atlantic SSTA could influence climate anomaly in Eurasia by exciting a downstream wave train (Liu et al. 2014; Wang and Zhang 2015). As shown by the wave activity flux (vectors; Fig. 10a), a wave source is observed over the North Atlantic around $30^{\circ} \mathrm{N}$, which spreads to western Europe and transports throughout Eurasia to the northeast of Asia and contributes to the above descripted anomalous centers. The wind anomalies at lower levels show very similar features (Fig. 10b). Two cyclonic wind anomalies located over the North Atlantic and the Ural Mountains, and two anticyclonic anomalies are observed over western Europe and northeastern Asia. These atmospheric circulations lead to the negative-positive-negative land precipitation pattern over Eurasia (Fig. 10c). The anomalous negative height center over the Ural Mountains favors upward movement in NWC, according to the equation of vertical motion (Holton 2004). Besides, the southeast wind anomalies at the southwest boundary of the anticyclone over northeastern Asia could bring water vapor to NWC. Thus, in this type of case, the MNA SSTA affect NWC WP variability by inducing an EU-like wave train.

When the El Niño-related SST exits individually, positive SLP anomalies are observed over large areas from Japan to western North Pacific (Fig. 12a). This indicates a decreased East Asia trough, which may cause a weaker than normal East Asian winter monsoon by reducing the pressure gradient between land and ocean (Wu and Wang 2002). Negative SLP anomalies are found over the northern North Pacific, implying an enhanced Aleutian low. The 500-hPa circulation anomalies (Fig. 12b) show very similar features as the SLP, with positive height anomalies occupying Japan and western North Pacific and negative anomalies locating over the northern North Pacific, demonstrating the equivalent barotropic responses of midlatitude 


\section{(a) Z500 \& WAF}

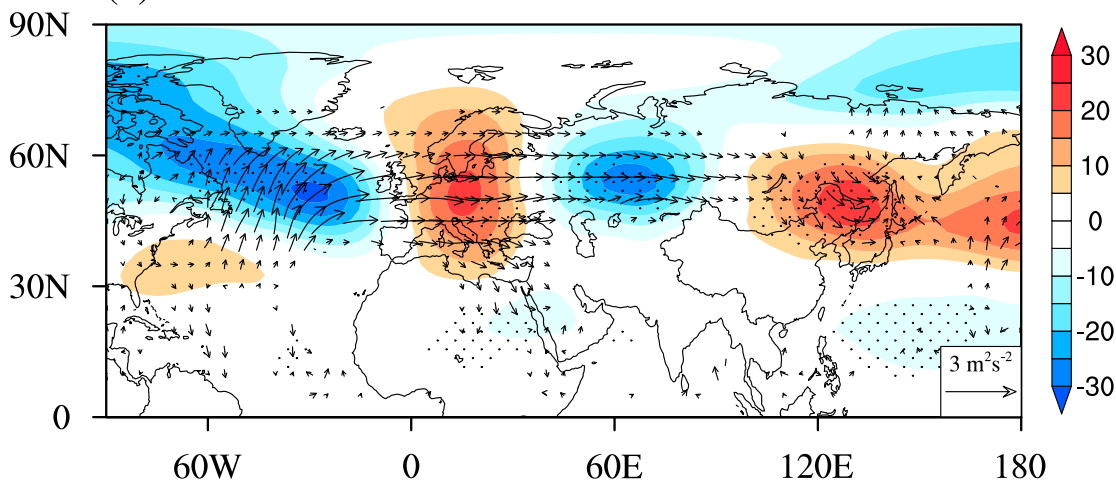

(b) 850 wind

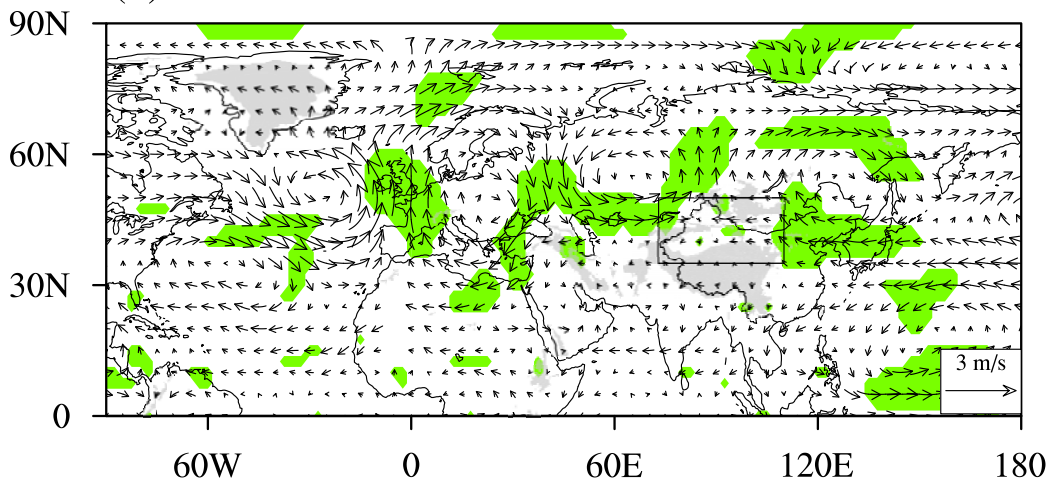

(c) PREC/L

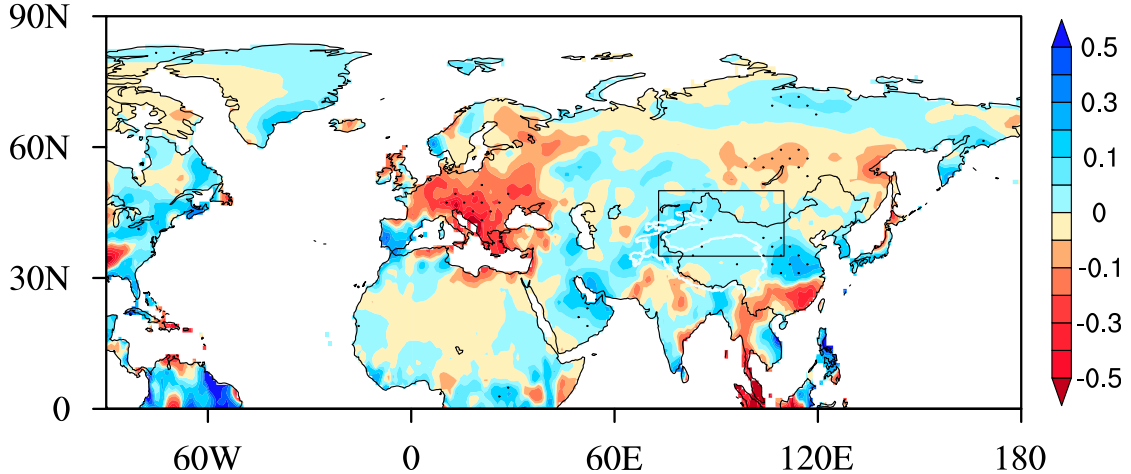

FIG. 10. Composited anomalies of winter (a) 500-hPa geopotential height (shading; gpm) and wave activity flux (vectors; $\mathrm{m}^{2} \mathrm{~s}^{-2}$ ), (b) $850-\mathrm{hPa}$ wind $\left(\mathrm{m} \mathrm{s}^{-1}\right)$, and (c) PREC/L precipitation $\left(\mathrm{mm} \mathrm{day}^{-1}\right.$ ) for MNA-SST only cases. The dots in (a) and (c) and green shading in (b) denote regions where the magnitude of composite anomalies is larger than one standard deviation of the individual anomalies with respect to the composite anomalies. The wave activity flux with magnitude less than $0.12 \mathrm{~m}^{2} \mathrm{~s}^{-2}$ is suppressed. The Chinese region in the rectangle box in (b) and (c) indicates the location of NWC. The gray shadings mark the terrain higher than $1500 \mathrm{~m}$ in (b) and the white curve in (c) indicates the Tibetan Plateau.

circulation to tropical SST forcing (Ting et al. 1996). The wind anomalies at $850 \mathrm{hPa}$ show a massive anticyclone over western North Pacific from tropical areas to the extratropics (Fig. 12c). Previous work indicated that the El Niño-related SSTA mainly affect East Asia climate variation through the WNPAC (Zhang and Sumi 2002; Zhou and Wu 2010), by stimulating a Rossby wave response to the cool convective latent heating in the tropical western Pacific (Zhang et al. 1996; Wang et al. 2000). As shown in Fig. 12c, two anticyclonic circulation 
(a) $700 \mathrm{hPa}$ Eady growth rate

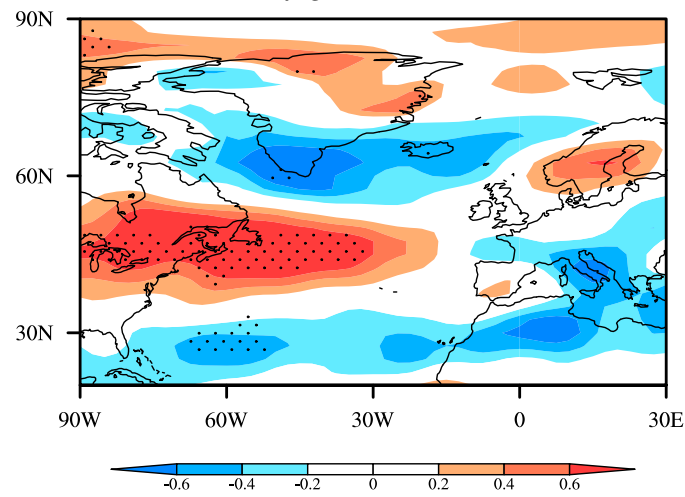

(b) $300 \mathrm{hPa}$ storm track

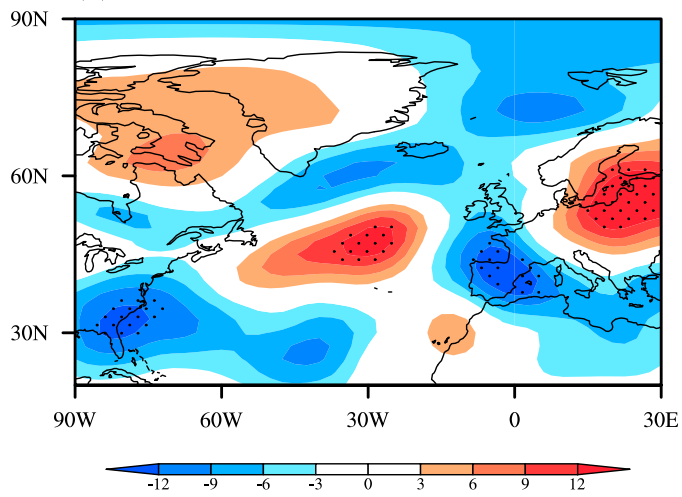

FIG. 11. Composited anomalies of winter (a) 700-hPa Eady growth rate and (b) 300-hPa storm track activity (m) for MNA-SST only cases. The dots denote regions where the magnitude of composite anomalies is large than one standard deviation of the individual anomalies with respect to the composite anomalies.

centers are observed over the Philippine Sea in the tropics and near the Kuroshio Extension in the midlatitudes, respectively. Southeasterly wind anomalies are observed at the northwest boundary of the midlatitude anticyclone, which reaches the eastern part of NWC. Moreover, southwesterly wind anomalies are seen in the southwestern part of NWC. These two wind anomalies could transport warm and wet air to NWC and give rise to the positive precipitation anomalies in the southern portion of NWC (Fig. 12d). Therefore, in the El NiñoSST only cases, the EAWM is weakened and the midlatitude portion of the WNPAC causes southwesterly wind anomalies that could transport amounts of water vapor to NWC. This result is consistent with previous work, in which scholars argued that in the El Niño mature winter the anomalous southwest wind anomalies to the northwestern side of the WNPAC could weaken the EAWM (e.g., Zhang et al. 1996) and lead to more than normal precipitation anomalies over most of China by causing northward transported water vapor ( $\mathrm{Li} \mathrm{1990;}$ Chen et al. 2000; Zhang et al. 2002). The CC between winter mean Niño-3.4 index and the EAWM index is 0.86 in ENSO-SST only cases, further verifying the close connection between ENSO and the EAWM. The results (a) SLP

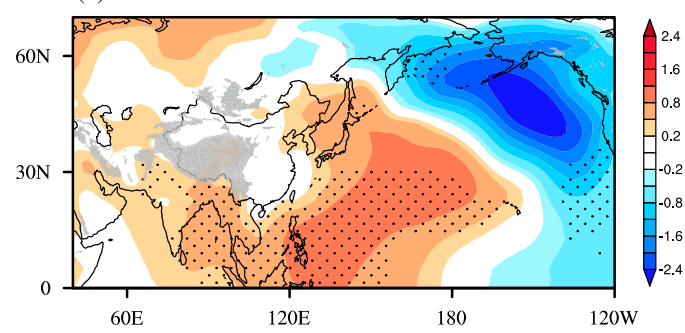

(c) $850 \mathrm{hPa}$ wind

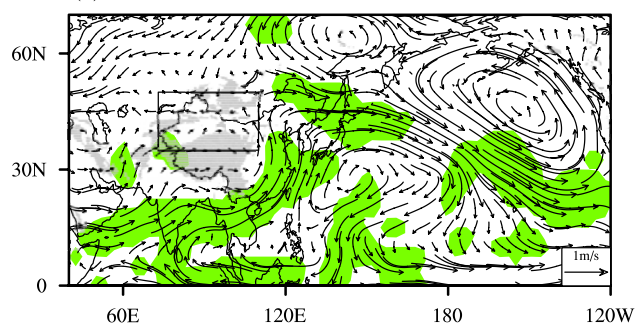

(b) Z500

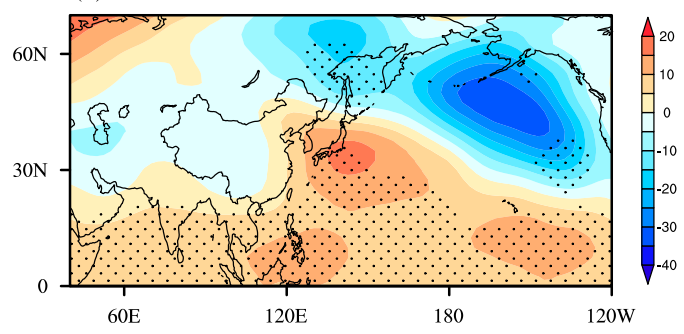

(d) PREC/L

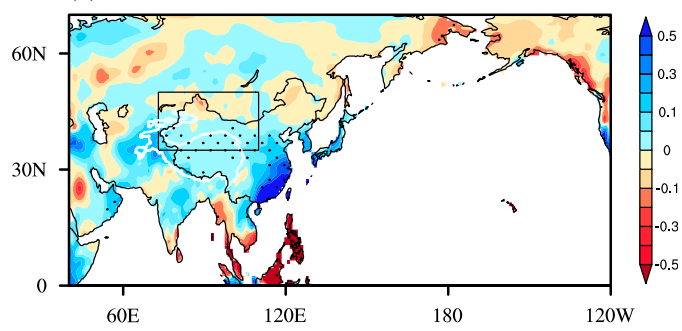

FIG. 12. Composite anomalies of winter (a) SLP (hPa), (b) 500-hPa geopotential height (gpm), (c) 850-hPa winds ( $\mathrm{m} \mathrm{s}^{-1}$ ), and (d) PREC/L precipitation $\left(\mathrm{mm} \mathrm{day}^{-1}\right.$ ) for ENSO-SST only cases. The dots in (a), (b), and (d) and green shading in (c) denote regions where the magnitude of composite anomalies is larger than one standard deviation of the individual anomalies with respect to the composite anomalies. The Chinese region in the rectangle boxes in (c) and (d) indicate the location of NWC. The gray shadings mark the terrain higher than $1500 \mathrm{~m}$ in (a) and (c) and the white curve in (d) indicates the Tibetan Plateau. 
(a) Z500

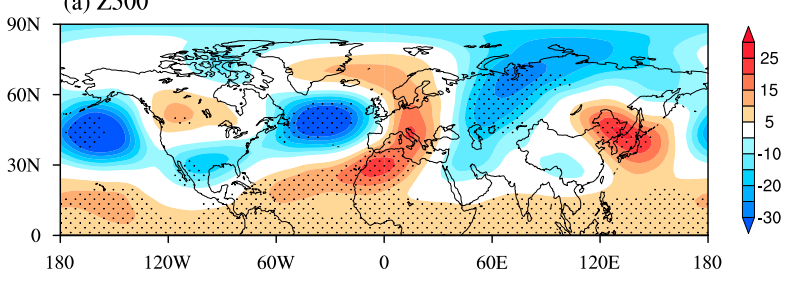

(b) $850 \mathrm{hPa}$ wind

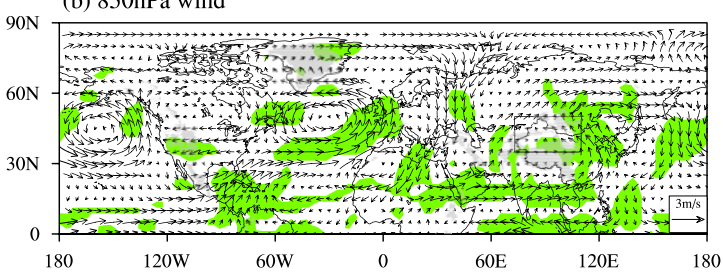

(c) PREC/L

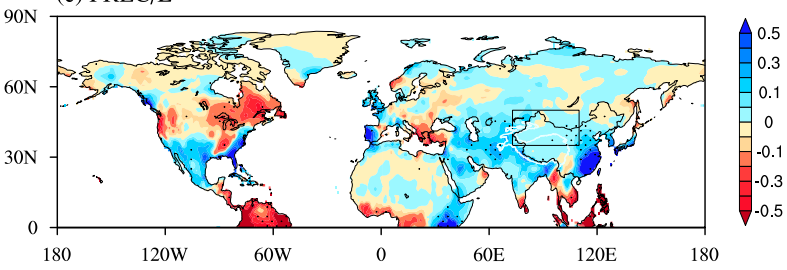

FIG. 13. Composite anomalies of winter (a) 500-hPa height (gpm), (b) $850-\mathrm{hPa}$ wind $\left(\mathrm{m} \mathrm{s}^{-1}\right)$, and (c) PREC/L precipitation $\left(\mathrm{mm} \mathrm{day}^{-1}\right)$ for Both-SST cases. Dots in (a) and (c) and green shading in (b) denote regions where the magnitude of composite anomalies is large than one standard deviation of the individual anomalies with respect to the composite anomalies. The Chinese region in the rectangle boxes in (b) and (c) indicates the location of NWC. The gray shadings mark the terrain higher than $1500 \mathrm{~m}$ in (b) and the white curve in (c) indicates the Tibetan Plateau.

for negative SSTA in the tropical eastern-central Pacific are opposite.

\section{b. Combined influences of MNA and Niño-3.4 SSTs}

Figure 13 shows the composite results for the cases when the MNA SSTA are significantly negative and the Niño-3.4 SSTA are positive. A prominent wave train is observed over the mid-to-high latitudes in the $\mathrm{NH}$ (Figs. 13a,b), which is quite similar to the circumglobal PNA-EU like teleconnection obtained by regression on the NWC WPI in P2 (Figs. 6f,g). The positive anomalies lie over the center of Canada, a large area from western Europe to North Africa, and Japan. The negative anomalies occupy large areas from the North Pacific across the southern United States to the North Atlantic, and areas from the Ural Mountains to the Caspian Sea. Corresponding to the circulation anomalies, weak and insignificant negative precipitation anomalies are found in most areas of Canada, northwestern Europe, the northern part of Africa, and northeastern Asia. Positive and prominent precipitation anomalies are observed over the southern United States and large regions over the center and southeast of Asia (Fig. 13c). NWC is dominated by a convergent circulation caused by southwesterly and southeasterly wind anomalies (Fig. 13b). As a result, positive winter precipitation anomalies occurred in the eastern and northwest part of NWC (Fig. 13c).

The above circulation anomalies indicate a concurrent contribution of the cold MNA SSTA and the warm ENSO shown in Fig. 9e. As discussed in the MNA-only cases, the EU-like wave train over Eurasia in Fig. 13a links to the negative SSTA in the MNA region and enhances the wet phase of the local dry circulation (Yang et al. 1984), leading to the convergent circulations, the ascent motion and positive precipitation anomaly over NWC. Besides, the anomalous anticyclone over Japan (Fig. 13b) may also be interpreted as a response to the anomalous heating over the equatorial eastern-central Pacific warming (Fig. 12; Wang et al. 2000). In addition, an atmospheric teleconnection is found from the North Pacific to the North Atlantic through North America. This teleconnection resembles the PNA-like pattern, a feature usually seen during ENSO (e.g., Enfield and Mayer 1997). In particular, a cyclonic center is observed over the midlatitude North Atlantic (Fig. 13b). Such a kind of wind anomalies could favor the formation and maintenance of the negative MNA SSTA through surface heat flux changes (Xie and Philander 1994; Chen et al. 2018). Some previous works revealed that the ENSO-related SST could affect the climate variability in Eurasian areas by exciting SSTA in the North Atlantic through atmospheric teleconnections (e.g., Alexander et al. 2002; Czaja et al. 2002; Wu et al. 2011). Thus, the effects of Niño-3.4 SST on NWC WP variation are felt through an indirect way by modulating the North Atlantic SST. And according to the temporal evolution of SSTA in Figs. 9b and 9f, the magnitude of the negative MNA SSTA in Both-cases (Fig. 9f) is much larger than that in the MNA-SST only cases (Fig. 9b), which also suggests an external forcing from the Niño-3.4 SSTA. To further examine the impact of preceding Niño-3.4 SST in the formation of the MNA SSTA, the SST, the 850-hPa wind anomalies and the surface heat flux obtained by regression on the normalized October-December (OND) Niño-3.4 index in Both-SST cases are investigated and shown in Fig. 14.

The positive SSTA in the equatorial eastern-central Pacific indicate an El Niño event (Figs. 14a,b). Negative SSTA are observed in the midlatitudes North Atlantic in early winter (Fig. 14a). A significant triple SST anomaly pattern formed in December-February (DJF) (Fig. 14b) and maintained to the subsequent early spring (not shown) in the North Atlantic, with positive SSTA locating in the subtropics and high latitudes and negative SSTA occupying the midlatitudes. The wind anomalies 
(a) SST

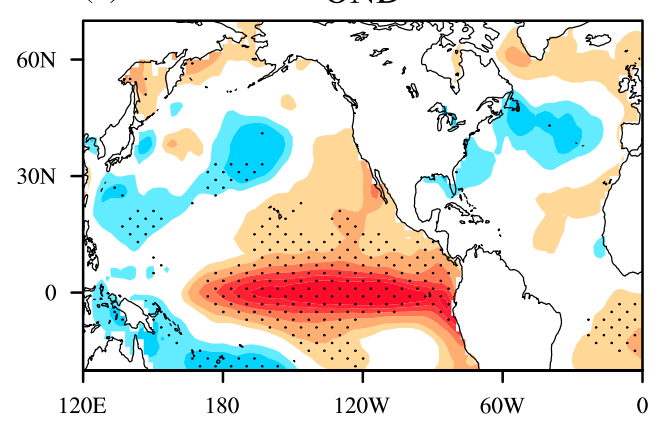

(c) $850 \mathrm{hPa}$ wind

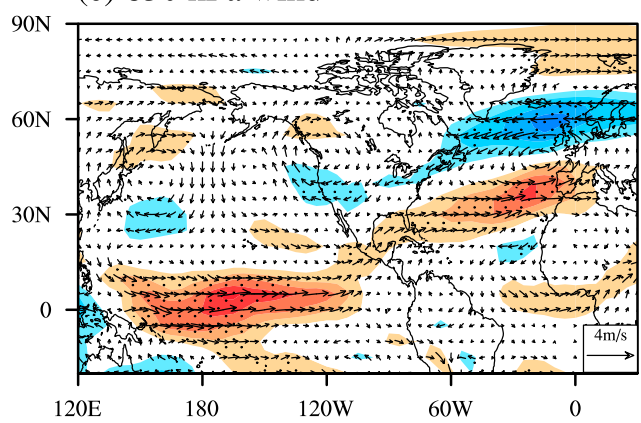

(e) nhtfl

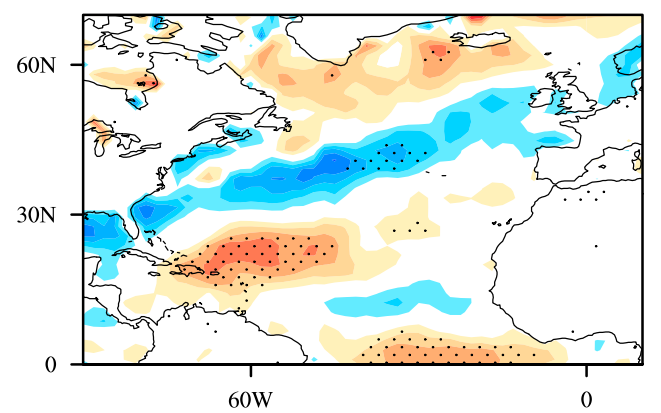

(b) SST

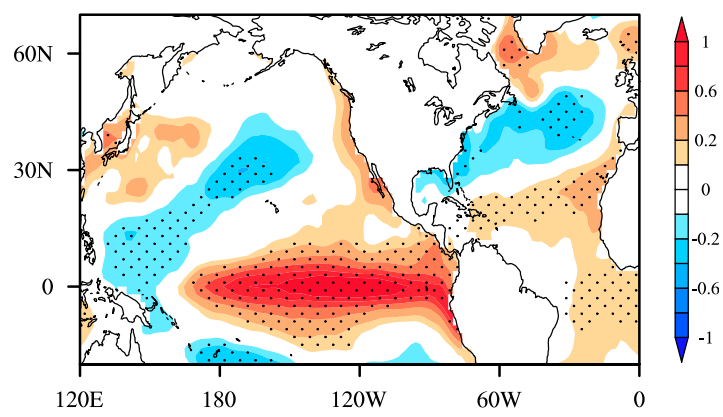

(d) $850 \mathrm{hPa}$ wind

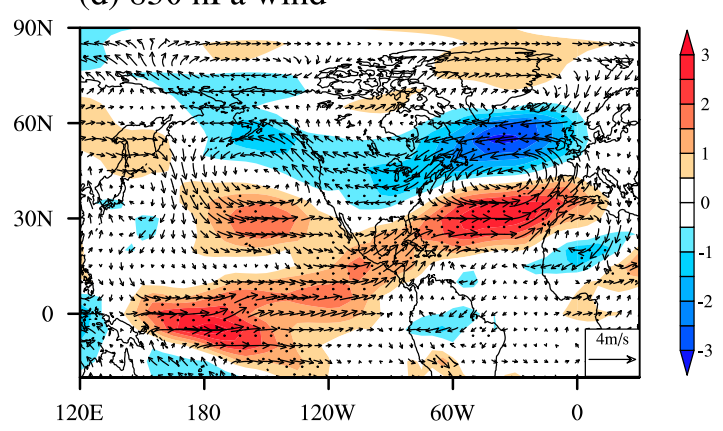

(f) nhtfl

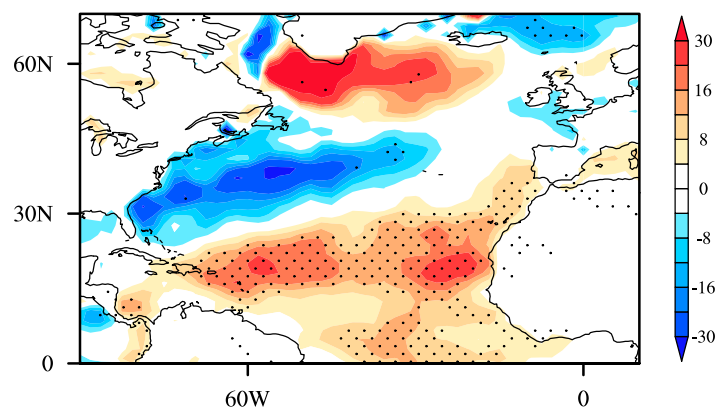

FIG. 14. Anomalies of (a),(b) SST $\left({ }^{\circ} \mathrm{C}\right)$, (c),(d) 850-hPa wind (vectors; $\mathrm{m} \mathrm{s}^{-1}$ ) and 850 -hPa zonal wind speed anomalies (shading; $\mathrm{m} \mathrm{s}^{-1}$ ), and (e),(f) surface net heat flux $\left(\mathrm{W} \mathrm{m}^{-2}\right)$ in OND and DJF obtained by regression on the normalized OND Niño-3.4 index in Both-SST cases. Dots denote regions where the magnitude of composite anomalies is large than one standard deviation of the individual anomalies with respect to the composite anomalies.

show a PNA-like teleconnection from the North Pacific to North America (e.g., Wallace and Gutzler 1981; Simmons et al. 1983), with cyclonic circulation anomalies over the North Pacific and the large areas from southeastern United State to the midlatitude North Atlantic and a anticyclonic circulation anomaly over North America (Figs. 14c,d). The air-sea interaction over the North Atlantic is further demonstrated in the surface net heat flux fields used the NCEP-NCAR datasets (Figs. 14e,f). Negative surface net heat flux anomalies are found in the MNA area, indicating a contribution to the formation and maintenance of the negative SSTA there. This negative heat flux is caused by the enhanced westerly wind near $30^{\circ} \mathrm{N}$ and the anomalous cyclone over the North Atlantic, which increases the latent heat losses through reinforcing the evaporation and reduces the incoming shortwave radiation by increasing cloud cover, respectively. The positive surface net heat flux anomalies over the subtropical regions and the high latitudes are related to the anomalous southwesterly wind in the subtropics and the easterly wind near $60^{\circ} \mathrm{N}$, which could suppress the ocean surface evaporation via weakening the climatological wind. Along with the enhancement of the wind anomalies (Fig. 14d), the surface net heat flux is also reinforced in DJF (Fig. 14f). These results are confirmed 
by the OAFlux data (not shown). Further analysis revealed that the surface net latent heat flux changes are dominated by the changes in the latent heat flux (figures not shown), similar to previous studies (Klein et al. 1999). In addition, the anomalous cyclone over the midlatitude North Atlantic may also excite upwelling through ocean dynamical process and contribute to the negative SSTA. Thus, the preceding El Niño-related SSTA may play an important role in the generation of the negative SST anomalies in the MNA area through the PNA-like teleconnection.

The above results suggest that there are two different processes connecting the El Niño events and NWC WP anomalies. One is a direct way through stimulating the anomalous anticyclonic circulation over Japan and the anomalous southerly wind anomalies. The other is an indirect way in which ENSO gives rise to SSTA in the MNA region through the "atmospheric bridge" in the first place, and then this SSTA causes the NWC wintertime precipitation anomaly by inducing circulation anomalies over Eurasia. The composite analysis also unravels that the MNA SSTA can affect NWC winter precipitation independent of ENSO via exciting a zonal wave train in the downstream. Another result to note from Table 2 is that the Both-SST cases mostly occur in the period of 1994-2010. That is, a warm ENSO is often accompanied by a negative MNA SST in most years during $\mathrm{P} 2$, and their impacts on NWC WP can add up in a positive interference pattern. Thus, the combination effects of the MNA and Niño-3.4 SSTA in P2 may cause the strengthened connections between NWC WP and the ENSO/MNA SSTA. We will investigate this in section 5.

\section{Possible reasons for the interdecadal change in the precipitation-SST relationships}

\section{a. The change in the connection between ENSO and MNA SST}

As speculated above, an interdecadal change may exit in the opposite-sign connection between the Niño-3.4 and the MNA SST around the mid-1990s, and their concurrent effects on the circulation anomalies may contribute to the enhanced connection with NWC WP. To examine the change of their relationship, a $17-\mathrm{yr}$ sliding correlation test is performed (Fig. 15). Before the mid-1990s, the CCs are weak and insignificant. In contrast, the CCs between the Niño-3.4 and the MNA SSTA are enhanced remarkably after the mid-1990s, verifying the closer relationship between Niño-3.4 and MNA SSTA. This result is consistent with Chen et al. (2018), who found a strengthened connection between the Niño-3.4 SST and the North Atlantic SST after the early 1990s, using a North Atlantic triple SST index (see their

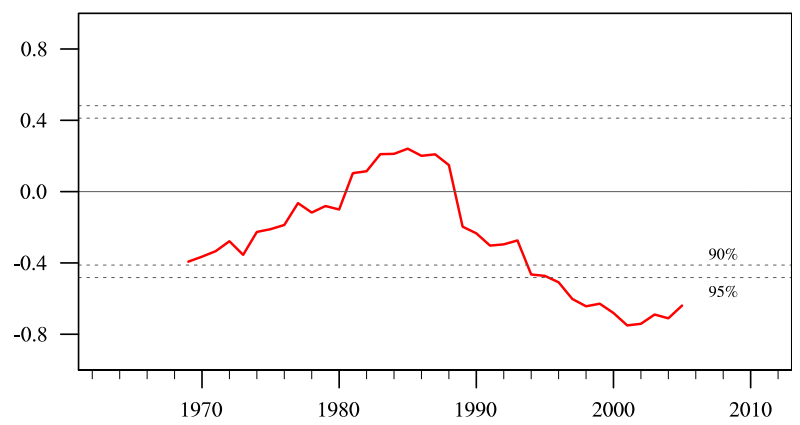

FIG. 15. Moving correlation coefficient of the OND Niño-3.4 SST and the NDJ MNA SST with a 17-yr window. The correlation coefficient is shown at the center year of the 17-yr window. The dashed gray lines indicate the $90 \%$ and $95 \%$ confidence level, based on the Student's $t$ test.

article in Fig. 15). Similar results are gained by using different lengths of window for the sliding correlation.

To see how the atmospheric circulation anomalies respond differently to the tropical eastern-central Pacific SST anomaly and how the North Atlantic SSTA respond to the different atmosphere circulations between 1975-91 and 1994-2010, we further calculate the evolution of the SSTA and wind anomalies related to the normalized OND Niño-3.4 index (Figs. 16 and 17). As shown in Fig. 16, an El Niño SST pattern is clearly observed in the tropical Pacific from winter to spring for both periods. The amplitude of the Niño-3.4 SST anomaly is stronger in 1994-2010 compared to that in 1975-91. Negative SSTA are seen over the North Atlantic in the preceding fall for P2 (Fig. 16e). A tripole SSTA pattern develops in the early winter, reaches its maximum in DJF, and weakens in the following spring, with positive SSTA locating in the subtropics and the high latitudes and negative anomalies in the midlatitudes (Figs. 16f-h). In contrast, the North Atlantic is dominated by a dipole SSTA from AugustOctober (ASO) to DJF in 1975-91 (Figs. 16a-c). In the preceding autumn, weak negative SSTA lie in the midlatitudes North Atlantic and positive SSTA are located along the western coast of North Africa (Fig. 16a). This dipole pattern reinforces in OND and DJF and shifts northward, with significant negative SSTA along the western coast of Europe and weak positive anomalies in the midlatitude North Atlantic (Figs. 16b,c). In the early spring, a tripole SST anomaly forms with remarkable positive SSTA in the tropics and weak positive anomalies in the midlatitudes, and negative SSTA along the southeast coast of North America (Fig. 16d). This tripole pattern is located much more southward than that in 1994-2010 (Figs. 16f-h).

The atmospheric circulation anomalies also show quite different features between the two periods (Fig. 17). During 1994-2010, an obvious North Atlantic Oscillation 
(a) ASO

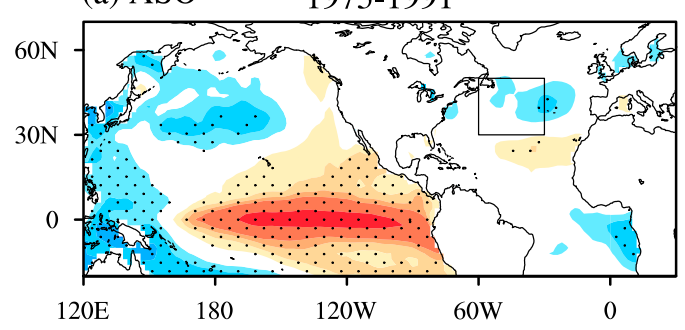

(b) OND

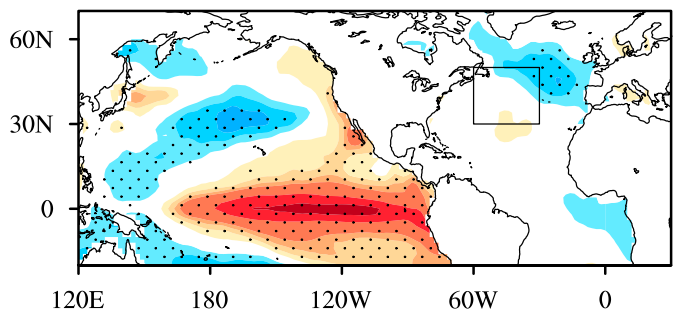

(c) DJF

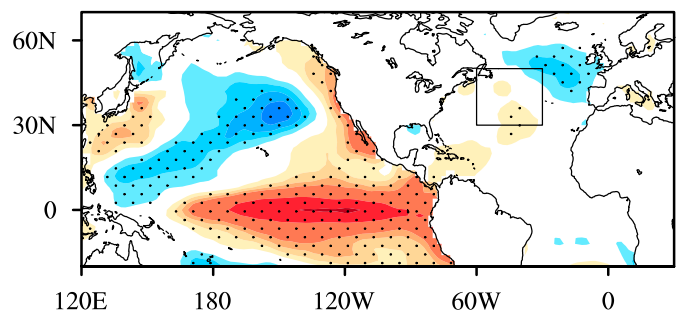

(d) FMA

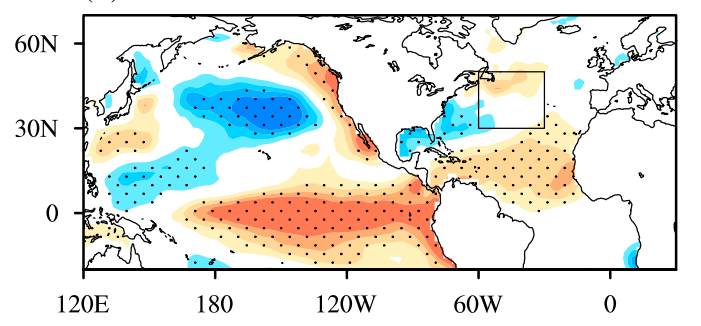

(e) ASO 1994-2010

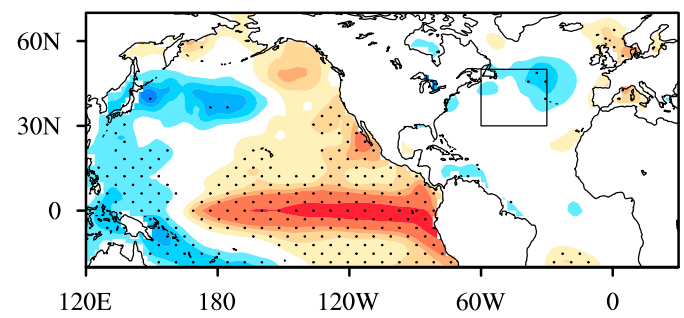

(f) OND

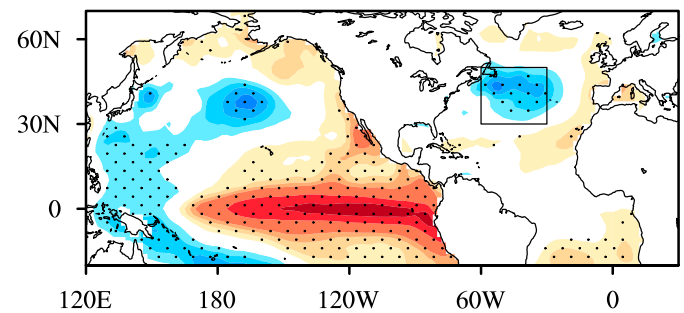

(g) DJF

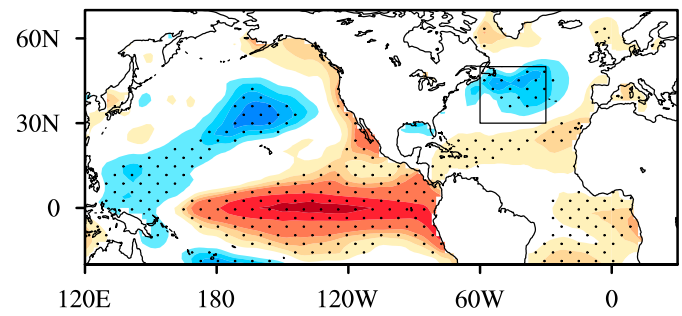

(h) FMA

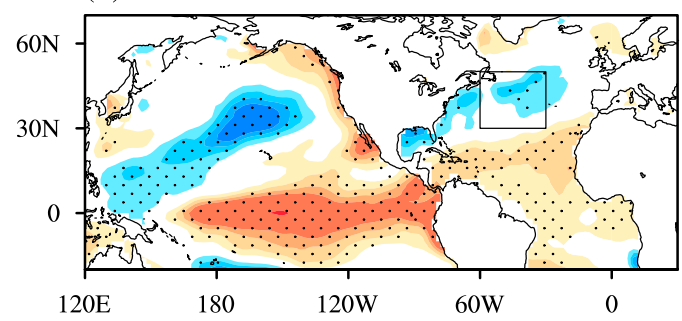

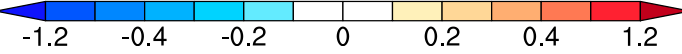

FIG. 16. Anomalies of SST $\left({ }^{\circ} \mathrm{C}\right)$ obtained by regression on the normalized OND Niño-3.4 index for the periods (left) 1975-91 and (right) 1994-2010: (a),(e) ASO, (b),(f) OND, (c),(g) DJF, and (d),(h) FMA. Dots denote regions significant at the $95 \%$ confidence level, based on the Student's $t$ test. Boxes indicate the region of the MNA region.

(NAO)-like pattern is observed over the North Atlantic in late fall and winter, with a strong cyclonic wind anomaly lying in the midlatitudes and a relatively weaker anticyclonic anomaly locating in the high latitudes (Figs. 17e-g). This atmospheric circulation anomaly could induce a tripole SST pattern (Figs. 16f-h) in the North Atlantic by modulating surface heat flux and oceanic advection (e.g., Marshall et al. 2001; Visbeck et al. 2003; Chen et al. 2015). In the early spring, the anticyclone vanished, and the cyclone weakened and shifted southward (vectors; Fig. 17h), contributing to the decrease of the tripole SST pattern in spring (Fig. 16h). Thus, the El Niñorelated SSTA may play an important role in the generation of the negative MNA SSTA during P2 by inducing a negative phase of NAO anomaly over the North Atlantic (e.g., Enfield and Mayer 1997; Brönnimann et al. 2007). In comparison, during 1975-91, a positive NAO-like pattern dominates the North Atlantic in late fall (Fig. 17b). The locations of the anomalous centers shift southward compared to the traditional NAO pattern. Accordingly, 
(a) ASO

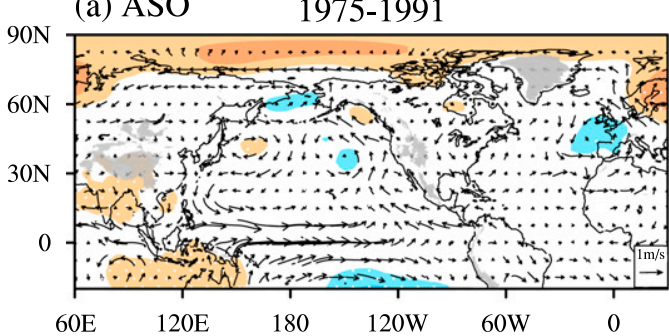

(b) OND

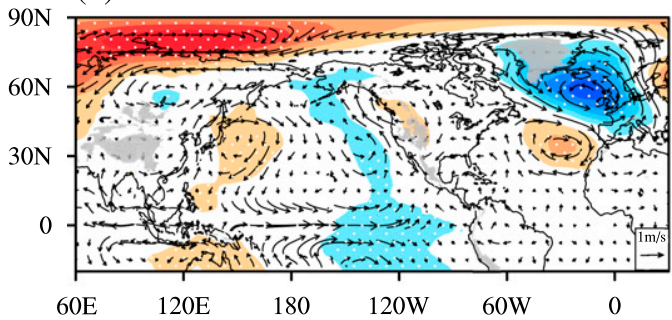

(c) DJF

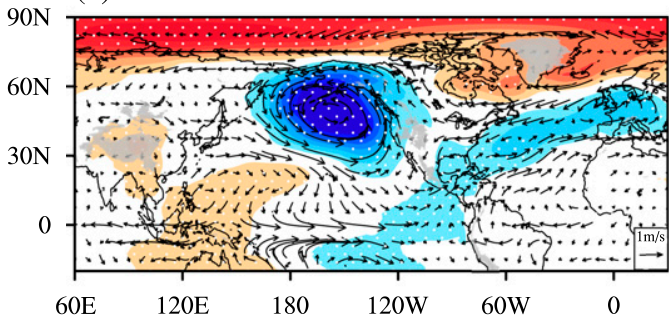

(d) FMA

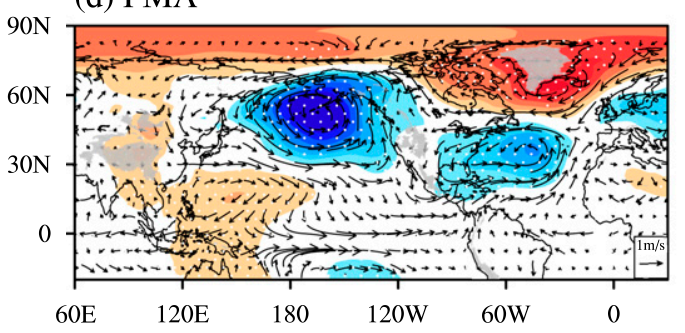

(e) ASO

$1994-2010$

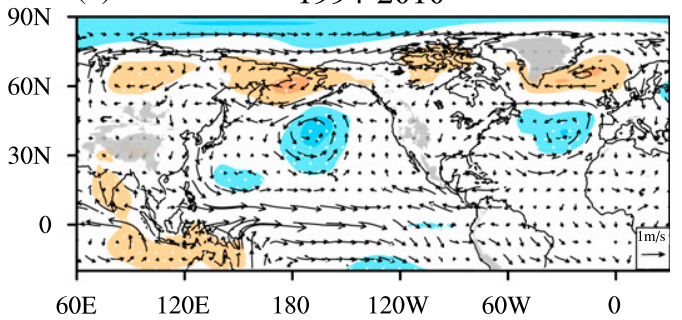

(f) OND

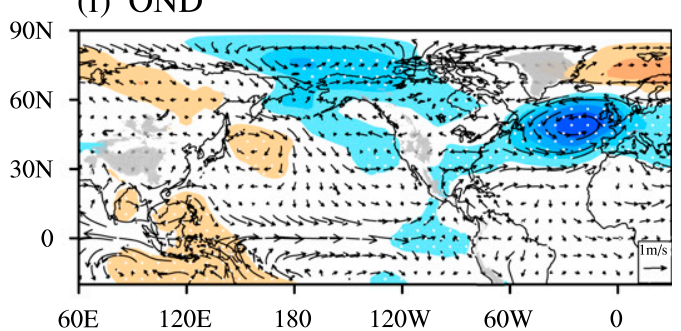

(g) DJF

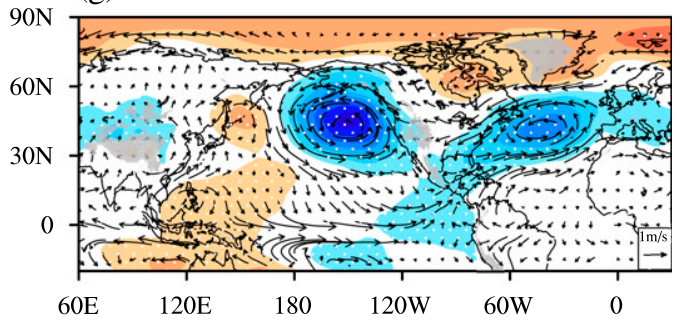

(h) FMA

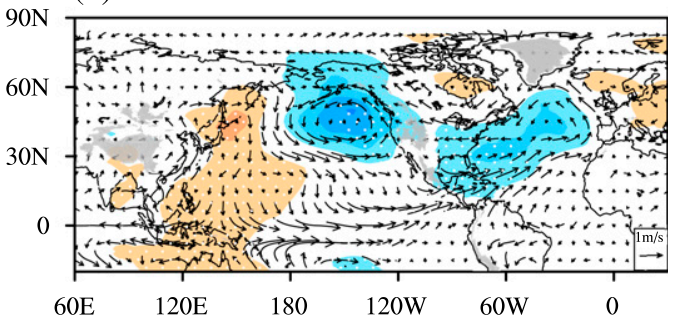

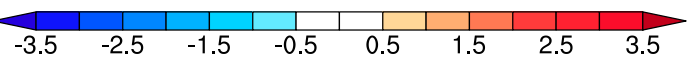

FIG. 17. As in Fig. 16, but for the anomalous SLP (shading; hPa) and $850-\mathrm{hPa}$ wind (vectors; $\mathrm{m} \mathrm{s}^{-1}$ ). The gray shadings mark the terrain higher than $1500 \mathrm{~m}$.

positive SSTA develop along the west coast of Europe and negative anomalies form in the midlatitudes North Atlantic (Fig. 16a). In DJF, this dipole pattern reversed and featured a negative NAO-like pattern (Fig. 17c), which may be a response to the ENSO-related teleconnection from the North Pacific to the North Atlantic. The cyclonic wind anomalies in the midlatitude North Atlantic are much weaker and located more southward than those in 1994-2010 (Figs. 17f,g). This anomalous pattern enhances in the early spring and shifts even southward (Fig. 17d), favoring the formation of the south shifted tripole SST anomaly pattern (Fig. 16d). Therefore, for 1975-91, the weaker and southward shifted circulation anomalies contribute to a weak positive SSTA in MNA.

As discussed above, the Niño-3.4 and the MNA SST indices have a remarkable negative correlationship during 1994-2010, their concurrent effects on the circulation anomalies contribute to the enhanced connections with NWC WP. Since the MNA SSTA could be forced by ENSO, a partial regression method is needed to verify the reality of their independent effects on NWC WP in this period. The coherent variability of Niño-3.4 (MNA SST) index is removed by means of a linear regression from the time series of the MNA SST (Niño-3.4) index as follows: 
(a) SST

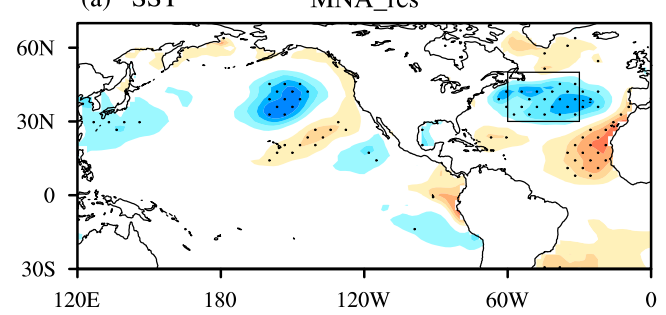

(b) Z500

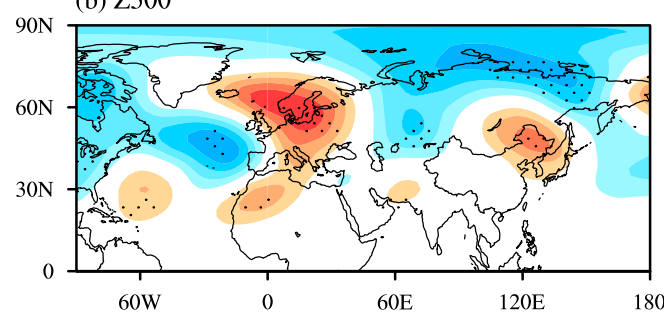

(c) 850 wind

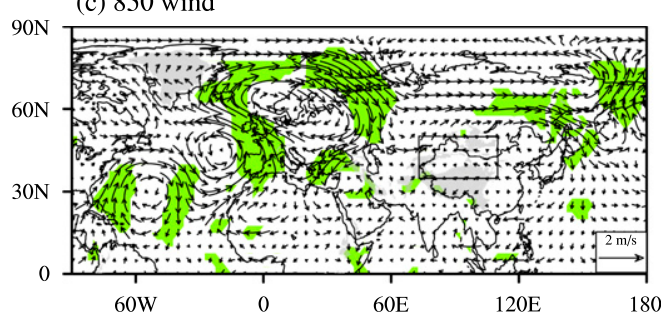

(d) PREC/L

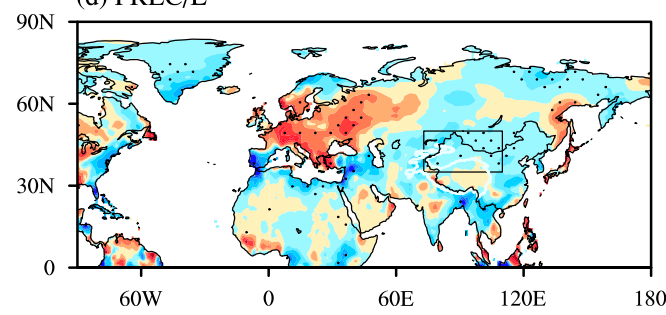

(e) SST NINO34_res
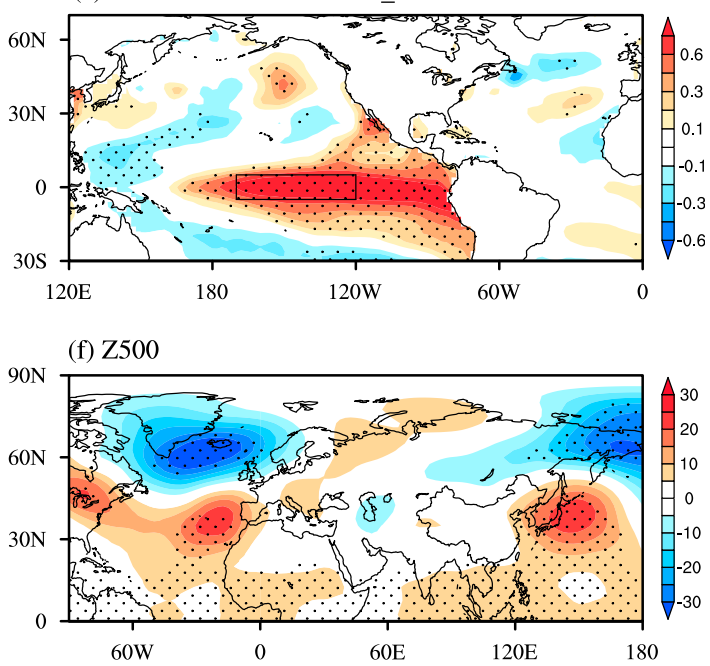

(g) 850 wind

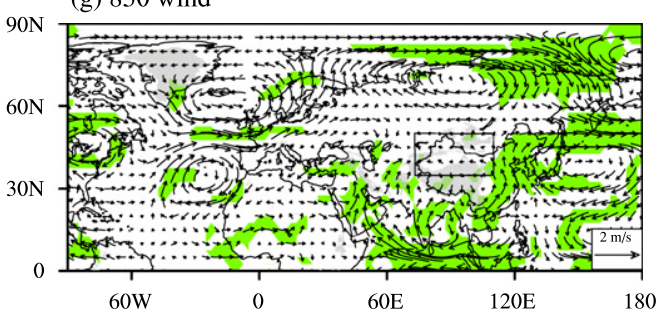

(h) PREC/L

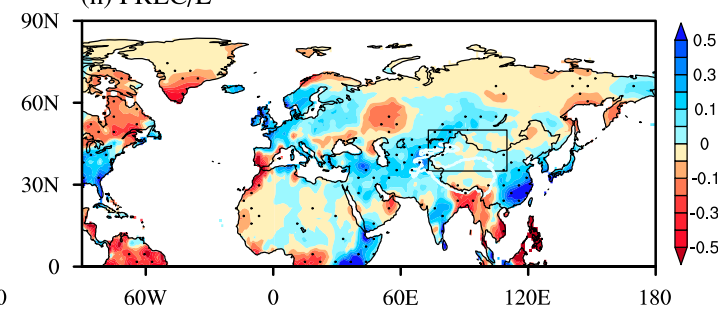

FIG. 18. Anomalies of winter (a),(e) SST $\left({ }^{\circ} \mathrm{C}\right)$, (b),(f) 500-hPa geopotential height (gpm), (c),(g) 850-hPa winds $\left(\mathrm{m} \mathrm{s}^{-1}\right)$, and (d), (h) PREC/L precipitation $\left(\mathrm{mm} \mathrm{day}^{-1}\right)$ obtained by regression on the (left) $\mathrm{MNA}_{\text {res }}$ and (right) Niño-3.4 res indices. The dotted regions and the green shading indicate the $95 \%$ confidence level, based on the Student's $t$ test. Box in (a) and (e) indicates the region of MNA SST and Niño-3.4 SST, respectively. The Chinese region in the rectangle boxes in (c), (d), (g), and (h) indicates the location of NWC. The gray shadings mark the terrain higher than $1500 \mathrm{~m}$ in (c) and (g), and the white curves in (d) and (h) indicate the Tibetan Plateau.

$$
\begin{aligned}
\text { MNA }_{\text {res }} & =\text { MNA }-r \times \text { Niño-3.4, } \\
\text { Niño-3. } 4_{\text {res }} & =\text { Niño-3.4 }-r \times \text { MNA, }
\end{aligned}
$$

where $r$ is the correlation coefficient between them.

After the ENSO signal is removed, the results obtained by regression on the $\mathrm{MNA}_{\text {res }}$ (Figs. 18a-d) are similar to the composite anomalies for MNA-SST only cases in Fig. 10. A negative anomalous center at 500-hPa height (Fig. 18b) is observed to the north of the negative SSTA over the midlatitudes North Atlantic (Fig. 18a). In the downstream, there is an EU-like teleconnection over
Eurasia, with two positive centers occupying western Europe and northeastern Asia and a negative center lying near the Ural Mountains. These circulation anomalies have smaller amplitude compared to those in Fig. 13 when both ENSO and the MNA SST anomalies exist, indicating an influence from the ENSO for BothSST cases. Southeastern wind anomalies at the southwest margin of the anticyclone over northeastern Asia (Fig. 18c) could bring water vapor to NWC and cause positive precipitation anomalies (Fig. 18d). After the MNA SST signal is removed, the results obtained by regression on the Niño-3.4 $4_{\text {res }}$ (Figs. 18e-h) are similar to 


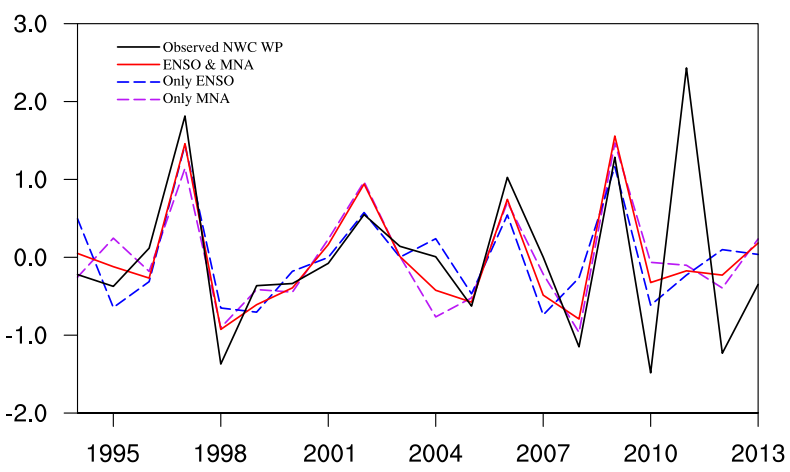

FIG. 19. The time series of the observed NWC WPI (solid black curve) and the predicted NWC WPI made by the empirical model using only Niño-3.4 index (dashed blue curve) or MNA index (dashed purple curve), and both Niño-3.4 and MNA indices (solid red curve)

those of the composite anomalies for ENSO-SST only cases in Fig. 12. Positive height anomalies occupy over Japan and western North Pacific at $500 \mathrm{hPa}$ (Fig. 18f). Strong southeasterly wind anomalies are observed to the southwest boundary of the midlatitude anticyclone, which reaches the eastern part of NWC (Fig. 18g). Together with the southwesterly wind anomalies to the western region of NWC, they would give rise to the positive precipitation anomalies in NWC (Fig. 18h).

\section{b. Prediction for NWC WP using a regression method}

To assess the capability of the values of ENSO and MNA SST in predicting the NWC WP variations, an empirical model is developed with multiple linear regression method for the period of 1994-2013 when the connections between NWC WP and the two SSTs are strong and significant. The empirical model is expressed as

$$
y=a_{0}+a_{1} x_{1}+a_{2} x_{2}+e,
$$

where $x_{1}$ and $x_{2}$ denote the Niño-3.4 index and the MNA index, respectively, $a_{0}, a_{1}$, and $a_{2}$ are the regression coefficients, and $e$ is the residual. The statistical crossvalidation test is applied when calculating the regression coefficients.

The hindcast results of the empirical model are shown in Fig. 19. Using both the Niño-3.4 and MNA indices, the temporal correlation coefficient (TCC) between the observational NWC WPI (solid black line) and the hindcast NWC WPI (solid red line) is 0.58 , indicating that the empirical model captures the variation in NWC WP reasonably well. For comparison purposes, empirical models established using only the Niño-3.4 index (dashed blue line) or the MNA index (dashed purple line) are also examined. The TCC between the observational NWC WPI and the hindcast NWC WPI used the Niño-3.4 index is 0.50 , while the TCC between the observational NWC WPI and the hindcast NWC WPI with the MNA index is 0.57 . The empirical model established for period 1961-2013 is also tested. However, the result is not significant. The TCC between the observational NWC WPI and the hindcast NWC WPI using both the Niño-3.4 and MNA indices is only 0.19 . This probably due to the weak connections between NWC WP and the two SSTs during 1975-91, and the TCC between the observational NWC WPI and hindcast NWC WPI is -0.75 at this period.

\section{Summary and discussion}

The present study reveals a significant interdecadal change in the relationship of the leading mode wintertime precipitation in NWC with the tropical easterncentral Pacific SST and midlatitude North Atlantic SST around the mid-1990s. Before the mid-1990s, the NWC WP had almost no connections to these two SSTs. By contrast, their relationship is enhanced sharply after the mid-1990s, when the NWC WP tends to be more (less) than normal during El Niño (La Niña) years and cold (warm) MNA SSTA years.

The atmospheric circulation anomalies associated with NWC WP show very different features between 1975-91 and 1994-2010. During 1975-91, the circulation anomalies are limited to high latitudes in the $\mathrm{NH}$ and feature an AO-like pattern. During 1994-2010, a circumglobal circulation anomaly pattern is observed over the mid-to-high latitudes in the $\mathrm{NH}$, with positive height anomalies over western Europe, Japan, and North America, and negative anomalies over the Ural Mountains, the North Pacific, and the North Atlantic, which resembles a conjunct PNA-EU pattern.

Further analysis reveals that the Niño-3.4 and the MNA SSTA can affect NWC WP variability by individual and in concert based on the composite method. In comparison, there are equal cases when the Niño-3.4 and the MNA SSTA contribute to the anomalous winter precipitation in NWC independently, which suggests a comparable impact from the two SSTAs. The MNA SST plays its individual role in NWC WP anomaly by exiting a zonal wave train over Eurasia, which stimulates the local dry circulation over NWC. The ENSO-related SST anomaly can affect NWC WP variability directly through inducing an anomaly anticyclonic (cyclonic) circulation over Japan and anomalous southerly (northerly) wind to the eastern boundary of NWC. In the Both-SST cases, the ENSO-MNA SSTAs act in concert in influencing NWC WP by the ways when they occur independently. Moreover, a PNA-like atmospheric teleconnection from the North Pacific to the North Atlantic is also observed in 
the Both-SST cases. This suggests that ENSO can give rise to the MNA SSTA through the atmospheric teleconnection first, and then this anomalous SST in MNA contributes to NWC winter precipitation anomaly by inducing circulation anomalies over the Eurasian continent.

The interdecadal change in the relationships between NWC WP and the ENSO-MNA SSTAs may owe to the enhanced connection between the Niño-3.4 and the MNA SST around the mid-1990s. It is found that an El Niño (a La Niña) event is usually followed by a negative (positive) SSTA in MNA after the mid-1990s. These SST anomalies can force a PNA-EU like anomalies in the $\mathrm{NH}$, which plays a key role in the amplitude of the dry circulation over NWC and causes significant precipitation responses in NWC. Thus, the collaborative influences of ENSO and the MNA SST on NWC WP result in the enhanced relationship between precipitation and the two SSTs after the mid-1990s. Further analysis shows that a hindcast of the empirical model using both the Niño-3.4 and MNA indices could well capture the variation in NWC WP during the second period.

In addition, differences of circulation anomalies in Fig. 17 can also be observed over the western North Pacific areas. In 1994-2010, the Aleutian low is enhanced and located in the eastern North Pacific from winter to early spring (Figs. 17g,h), and positive SLP anomalies are seen over the western North Pacific and Japan. Besides, there are negative SLP anomalies over Siberian area (Fig. 17g), indicating a weaker than normal Siberian high. Accordingly, southerly wind anomalies penetrate northward along East Asia to almost $50^{\circ} \mathrm{N}$, which could enhance the moisture supply to the NWC region and contribute to above-normal precipitation. In 1975-91, negative height anomalies occupy throughout the entire North Pacific, and weak positive anomalies are restricted to the south of Japan (Figs. 17c,d). Moreover, positive SLP anomalies are observed over the Siberian region, indicating an enhanced Siberian high. Thus, the southerly wind anomalies are confined to south of $30^{\circ} \mathrm{N}$ (Figs. 17c,d). Those differences may be due to the phase and amplitude of the PDO (e.g., Mantua et al. 1997; Wang et al. 2008; Chen et al. 2013). During 1975-91, the PDO is positive with strong amplitude (not shown; Mantua et al. 1997; Minobe 1999). As a result, the WNPAC related to the El Niño events is confined to the south of the Philippines according to Wang et al. (2008). Therefore, the southerly wind anomalies are limited to south of $30^{\circ} \mathrm{N}$ during 1975-91 (Figs. 17c,d). In 1994-2010, the amplitude of the PDO decreased and reversed to a negative phase around the late 1990s (Chavez et al. 2003), which is conducive to the enhanced southerly wind anomalies that penetrate northward to most of eastern NWC, leading to the enhanced connection between NWC winter precipitation and ENSO.

The results obtained in the present study are mainly based on the regression and composite analysis. Some numerical experiments will be needed in future studies to confirm the current conclusions. Another aspect that remains is the reason for the enhanced connection between the ENSO SST and the MNA SST, and to what extent an ENSO event can precondition the MNA SST, since the regional air-sea interaction also plays an important role in the formation and maintenance of the North Atlantic SSTA (Marshall et al. 2001; Czaja et al. 2002).

Acknowledgments. This study is supported by the National Key Research and Development Program of China Grant 2016YFA0600603.

\section{REFERENCES}

Alexander, M. A., I. Bladé, M. Newman, J. R. Lanzante, N.-C. Lau, and J. D. Scott, 2002: The atmospheric bridge: The influence of ENSO teleconnections on air-sea interaction over the global oceans. J. Climate, 15, 2205-2231, https://doi.org/10.1175/15200442(2002)015<2205:TABTIO>2.0.CO;2.

Blackmon, M. L., J. M. Wallace, N.-C. Lau, and S. L. Mullen, 1977: An observational study of the Northern Hemisphere wintertime circulation. J. Atmos. Sci., 34, 1040-1053, https://doi.org/ 10.1175/1520-0469(1977)034<1040:AOSOTN>2.0.CO;2.

Brönnimann, S., E. Xoplaki, C. Casty, A. Pauling, and J. Luterbacher, 2007: ENSO influence on Europe during the last centuries. Climate Dyn., 28, 181-197, https://doi.org/10.1007/s00382-0060175-z.

Cai, W., P. van Rensch, T. Cowan, and A. Sullivan, 2010: Asymmetry in ENSO teleconnection with regional rainfall, its multidecadal variability, and impact. J. Climate, 23, 4944-4955, https://doi.org/ 10.1175/2010JCLI3501.1.

,,,--- and H. H. Hendon, 2012: An asymmetry in the IOD and ENSO teleconnection pathway and its impact on Australian climate. J. Climate, 25, 6318-6329, https://doi.org/ 10.1175/JCLI-D-11-00501.1.

Chavez, F. P., J. Ryan, S. E. Lluch-Cota, and C. M. Niquen, 2003: From anchovies to sardines and back: Multidecadal change in the Pacific Ocean. Science, 299, 217-221, https://doi.org/ 10.1126/science.1075880.

Chen, M. Y., P. P. Xie, J. E. Janowiak, and P. A. Arkin, 2002: Global land precipitation: A 50-yr monthly analysis based on gauge observations. J. Hydrometeor., 3, 249-266, https:// doi.org/10.1175/1525-7541(2002)003<0249:GLPAYM> 2.0.CO;2.

Chen, S. F., and R. G. Wu, 2017: Interdecadal changes in the relationship between interannual variations of spring North Atlantic SST and Eurasian surface air temperature. J. Climate, 30, 3771-3787, https://doi.org/10.1175/JCLI-D-16-0477.1.

,-- , and W. Chen, 2015: The changing relationship between interannual variations of the North Atlantic Oscillation and northern tropical Atlantic SST. J. Climate, 28, 485-504, https:// doi.org/10.1175/JCLI-D-14-00422.1. 
,$--\frac{1}{-}$, and Y. Liu, 2016: Dominant modes of interannual variability in Eurasian surface air temperature during boreal spring. J. Climate, 29, 1109-1125, https:/doi.org/10.1175/JCLI-D-15-0524.1.

,-- W. Chen, and S. L. Yao, 2018: Enhanced linkage between Eurasian winter and spring dominant modes of atmospheric interannual variability since the early 1990s. J. Climate, 31, 3575-3595, https://doi.org/10.1175/JCLI-D-17-0525.1.

Chen, W., H. F. Graf, and R. H. Huang, 2000: The interannual variability of East Asian winter monsoon and its relation to the summer monsoon. Adv. Atmos. Sci., 17, 48-60, https:// doi.org/10.1007/s00376-000-0042-5.

_ - J. Feng, and R. G. Wu, 2013: Roles of ENSO and PDO in the link of the East Asian winter monsoon to the following summer monsoon. J. Climate, 26, 622-635, https://doi.org/10.1175/ JCLI-D-12-00021.1.

Czaja, A., P. van der Vaart, and J. Marshall, 2002: A diagnostic study of the role of remote forcing in tropical Atlantic variability. J. Climate, 15, 3280-3290, https://doi.org/10.1175/15200442(2002)015<3280:ADSOTR>2.0.CO;2.

Duchon, C. E., 1979: Lanczos filtering in one and two dimensions. J. Appl. Meteor., 18, 1016-1022, https://doi.org/10.1175/15200450(1979)018<1016:LFIOAT>2.0.CO;2.

Enfield, D. B., and D. A. Mayer, 1997: Tropical Atlantic sea surface temperature variability and its relation to El Niño-Southern Oscillation. J. Geophys. Res., 102, 929-945, https://doi.org/ 10.1029/96JC03296.

Fisher, R. A., 1921: On the 'probable error' of a coefficient of correlation deduced from a small sample. Metron, 1, 3-32.

Gambo, K., L. Lu, and W. J. Li, 1987: Numerical simulation of Eurasian teleconnection pattern in atmospheric circulation during the Northern Hemisphere winter. Adv. Atmos. Sci., 4, 385-394, https://doi.org/10.1007/BF02656739.

Giannini, A., Y. Kushnir, and M. A. Cane, 2000: Interannual variability of Caribbean rainfall, ENSO, and the Atlantic Ocean. J. Climate, 13, 297-311, https://doi.org/10.1175/1520-0442(2000) 013<0297:IVOCRE>2.0.CO;2.

_ , J. C. H. Chiang, M. A. Cane, Y. Kushnir, and R. Seager, 2001: The ENSO teleconnection to the tropical Atlantic Ocean: Contributions of the remote and local SSTs to rainfall variability in the tropical Americas. J. Climate, 14, 4530-4544, https:// doi.org/10.1175/1520-0442(2001)014<4530:TETTTT>2.0.CO;2.

Hatzaki, M., and R. G. Wu, 2015: The south-eastern Europe winter precipitation variability in relation to the North Atlantic SST. Atmos. Res., 152, 61-68, https://doi.org/10.1016/j.atmosres.2013.10.008.

Holton, J. R., 2004: An Introduction to Dynamic Meteorology. Academic Press, 529 pp.

Horel, J. D., and J. M. Wallace, 1981: Planetary-scale atmospheric phenomena associated with the Southern Oscillation. Mon. Wea. Rev., 109, 813-829, https://doi.org/10.1175/15200493(1981)109<0813:PSAPAW>2.0.CO;2.

Huang, B. H., P. S. Schopf, and Z. Q. Pan, 2002: The ENSO effect on the tropical Atlantic variability: A regionally coupled model study. Geophys. Res. Lett., 29, 2039, https://doi.org/ 10.1029/2002GL014872.

Kalnay, E., and Coauthors, 1996: The NCEP/NCAR 40-Year Reanalysis Project. Bull. Amer. Meteor. Soc., 77, 437-471, https://doi.org/ 10.1175/1520-0477(1996)077<0437:TNYRP>2.0.CO;2.

King, A. D., L. V. Alexander, and M. G. Donat, 2013: Asymmetry in the response of eastern Australia extreme rainfall to low-frequency Pacific variability. Geophys. Res. Lett., 40, 2271-2277, https://doi.org/10.1002/grl.50427.

Klein, S. A., B. J. Soden, and N.-C. Lau, 1999: Remote sea surface temperature variations during ENSO: Evidence for a tropical atmospheric bridge. J. Climate, 12, 917-932, https://doi.org/ 10.1175/1520-0442(1999)012<0917:RSSTVD>2.0.CO;2.

Kushnir, Y., W. A. Robinson, I. Bladé, N. M. J. Hall, S. Peng, and R. Sutton, 2002: Atmospheric GCM response to extratropical SST anomalies: Synthesis and evaluation. J. Climate, 15, 2233-2256, https://doi.org/ 10.1175/1520-0442(2002)015<2233:AGRTES>2.0.CO;2.

Lau, N. C., and E. O. Holopainen, 1984: Transient eddy forcing of the time mean flow as identified by geopotential tendencies. J. Atmos. Sci., 41, 313-328, https://doi.org/10.1175/15200469(1984)041<0313:TEFOTT>2.0.CO;2.

Li, C. Y., 1990: Interaction between anomalous winter monsoon in East Asia and El Niño events. Adv. Atmos. Sci., 7, 36-46, https://doi.org/10.1007/BF02919166.

Lindzen, R. S., and B. Farrell, 1980: A simple approximate result for the maximum growth rate of baroclinic instabilities. J. Atmos. Sci., 37, 1648-1654, https://doi.org/10.1175/15200469(1980)037<1648:ASARFT>2.0.CO;2.

Liu, Y. Y., L. Wang, W. Zhou, and W. Chen, 2014: Three Eurasian teleconnection patterns: Spatial structures, temporal variability, and associated winter climate anomalies. Climate Dyn., 42, 2817-2839, https://doi.org/10.1007/s00382-014-2163-z

Mantua, N. J., S. R. Hare, Y. Zhang, J. M. Wallace, and R. C. Francis, 1997: A Pacific interdecadal climate oscillation with impacts on salmon production. Bull. Amer. Meteor. Soc., 78, 1069-1079, https://doi.org/10.1175/1520-0477(1997)078<1069: APICOW $>2.0 . \mathrm{CO} ; 2$

Marshall, J., and Coauthors, 2001: North Atlantic climate variability: Phenomena, impacts and mechanisms. Int. J. Climatol., 21, 1863-1898, https://doi.org/10.1002/joc.693.

Minobe, S., 1999: Resonance in bidecadal and pentadecadal climate oscillations over the North Pacific: Role in climatic regime shifts. Geophys. Res. Lett., 26, 855-858, https://doi.org/ 10.1029/1999GL900119.

Nakamura, H., M. Tanaka, and J. M. Wallace, 1987: Horizontal structure and energetics of Northern Hemisphere wintertime teleconnection patterns. J. Atmos. Sci., 44, 3377-3391, https:// doi.org/10.1175/1520-0469(1987)044<3377:HSAEON>2.0. $\mathrm{CO} ; 2$.

Peng, S. L., and J. S. Whitaker, 1999: Mechanisms determining the atmospheric response to midlatitude SST anomalies. J. Climate, 12, 1393-1408, https://doi.org/10.1175/1520-0442(1999)012<1393: MDTART $>2.0 . \mathrm{CO} ; 2$.

Saravanan, R., and P. Chang, 2000: Interaction between tropical Atlantic variability and El Niño-Southern Oscillation. J. Climate, 13, 2177-2194, https://doi.org/10.1175/1520-0442(2000)013<2177: IBTAVA $>2.0 . \mathrm{CO} ; 2$.

Sardeshmukh, P. D., and B. J. Hoskins, 1988: The generation of global rotational flow by steady idealized tropical divergence. J. Atmos. Sci., 45, 1228-1251, https://doi.org/10.1175/15200469(1988)045<1228:TGOGRF > 2.0.CO;2.

Simmons, A. J., J. M. Wallace, and G. W. Branstator, 1983: Barotropic wave propagation and instability, and atmospheric teleconnection patterns. J. Atmos. Sci., 40, 1363-1392, https:// doi.org/10.1175/1520-0469(1983)040<1363:BWPAIA > 2.0. $\mathrm{CO} ; 2$.

Smith, T. M., R. W. Reynolds, T. C. Peterson, and L. Lawrimore, 2008: Improvements to NOAA's historical merged landocean surface temperature analysis (1880-2006). J. Climate, 21, 2283-2296, https://doi.org/10.1175/2007JCLI2100.1.

Spence, J. M., M. A. Taylor, and A. A. Chen, 2004: The effect of concurrent sea-surface temperature anomalies in the tropical Pacific and Atlantic on Caribbean rainfall. Int. J. Climatol., 24, 1531-1541, https://doi.org/10.1002/joc.1068. 
Takaya, K., and H. Nakamura, 2001: A formulation of a phaseindependent wave-activity flux for stationary and migratory quasi-geostrophic eddies on a zonally varying basic flow. J. Atmos. Sci., 58, 608-627, https://doi.org/10.1175/15200469(2001)058<0608:AFOAPI > 2.0.CO;2.

Thompson, D. W. J., and J. M. Wallace, 2000: Annular modes in the extratropical circulation. Part I: Month-to-month variability. J. Climate, 13, 1000-1016, https://doi.org/10.1175/1520-0442(2000) 013<1000:AMITEC $>2.0$. CO; 2 .

Ting, M. F., M. P. Hoerling, T. Y. Xu, and A. Kumar, 1996: Northern Hemisphere teleconnection patterns during extreme phases of the zonal-mean circulation. J. Climate, 9, 2614-2633, https:// doi.org/10.1175/1520-0442(1996)009<2614:NHTPDE > 2.0. $\mathrm{CO} ; 2$.

Trenberth, K. E., and J. W. Hurrell, 1994: Decadal atmosphereocean variations in the Pacific. Climate Dyn., 9, 303-319, https://doi.org/10.1007/BF00204745.

Visbeck, M., E. P. Chassignet, R. G. Curry, T. L. Delworth, R. R. Dickson, and G. Krahmann, 2003: The ocean's response to North Atlantic Oscillation variability. The North Atlantic Oscillation: Climatic Significance and Environmental Impact, Geophys. Monogr., Vol. 134, Amer. Geophys. Union, 113145.

Wallace, J. M., and D. S. Gutzler, 1981: Teleconnections in the geopotential height field during the Northern Hemisphere winter. Mon. Wea. Rev., 109, 784-812, https://doi.org/10.1175/ 1520-0493(1981)109<0784:TITGHF $>2.0$.CO;2.

Wang, B., R. G. Wu, and X. H. Fu, 2000: Pacific-East Asian teleconnection: How does ENSO affect East Asian climate? J. Climate, 13, 1517-1536, https://doi.org/10.1175/1520-0442(2000)013<1517: PEATHD $>2.0 . \mathrm{CO} ; 2$.

Wang, H. J., and S. P. He, 2012: Weakening relationship between East Asian winter monsoon and ENSO after mid-1970s. Chin. Sci. Bull., 57, 3535-3540, https://doi.org/10.1007/s11434-0125285-x.

Wang, L., and J. Feng, 2011: Two major modes of the wintertime precipitation over China (in Chinese). Chin. J. Atmos. Sci., 35, 1105-1116.

, W. Chen, and R. H. Huang, 2008: Interdecadal modulation of PDO on the impact of ENSO on the East Asian winter monsoon. Geophys. Res. Lett., 35, L20702, https://doi.org/ 10.1029/2008GL035287.

Wang, N., and Y. C. Zhang, 2015: Evolution of Eurasian teleconnection pattern and its relationship to climate anomalies in China. Climate Dyn., 44, 1017-1028, https://doi.org/10.1007/ s00382-014-2171-z.

Wu, B. Y., and J. Wang, 2002: Winter Arctic Oscillation, Siberian high and East Asian winter monsoon. Geophys. Res. Lett., 29, 1897, https://doi.org/10.1029/2002GL015373.

Wu, R. G., and B. P. Kirtman, 2011: Caribbean Sea rainfall variability during the rainy season and relationship to the equatorial Pacific and tropical Atlantic SST. Climate Dyn., 37, 1533-1550, https://doi.org/10.1007/s00382-010-0927-7.
_ S. Yang, S. Liu, L. Sun, Y. Lian, and Z. T. Gao, 2010: Changes in the relationship between northeast China summer temperature and ENSO. J. Geophys. Res., 115, D21107, https:// doi.org/10.1029/2010JD014422.

,,,,---- , and —, 2011: Northeast China summer temperature and north Atlantic SST. J. Geophys. Res., 116, D16116, https://doi.org/10.1029/2011JD015779.

Xie, S. P., and S. G. H. Philander, 1994: A coupled ocean-atmosphere model of relevance to the ITCZ in the eastern Pacific. Tellus, 46A, 340-350, https://doi.org/10.3402/tellusa.v46i4.15484.

Yang, S. G., B. Y. Zhu, and G. C. Xu, 1984: The circulation characteristic of wet and dry monthly precipitation in Gansu Province (in Chinese). Gansu Meteor., 4, 8-10.

Yin, X. X., and L. T. Zhou, 2018: Dominant modes of wintertime precipitation variability in northwest China and the association with circulation anomalies and sea surface temperature. Int. J. Climatol., 38, 4860-4874, https://doi.org/10.1002/joc.5703.

— the central Pacific ENSO on the subsequent north tropical Atlantic spring SST variability around the mid-1980s. Climate Dyn., 53, 879-893, https://doi.org/10.1007/s00382-019-04618-2.

Zhang, C. J., J. N. Xie, D. L. Li, and H. Guo, 2002: Effect of east Asia monsoon on drought climate of NWC (in Chinese). Plateau Meteor., 21, 193-198.

Zhang, L., K. Fraedrich, X. H. Zhu, F. Sielmann, and X. F. Zhi, 2015: Interannual variability of winter precipitation in southeast China. Theor. Appl. Climatol., 119, 229-238, https:// doi.org/10.1007/s00704-014-1111-5.

Zhang, Q., Y. Q. Hu, X. Y. Cao, and W. M. Liu, 2000: On some problems of arid climate system of northwest China (in Chinese). J. Desert Res., 20, 357-362.

Zhang, R. H., and A. Sumi, 2002: Moisture circulation over East Asia during El Niño episode in northern winter, spring and autumn. J. Meteor. Soc. Japan, 80, 213-227, https://doi.org/ $10.2151 / \mathrm{jmsj} .80 .213$.

,-- , and M. Kimoto, 1996: Impact of El Niño on the East Asian monsoon: A diagnostic study of the ' $86 / 87$ and ' $91 / 92$ events. J. Meteor. Soc. Japan, 74, 49-62, https://doi.org/ 10.2151/jmsj1965.74.1_49.

Zhou, L. T., 2011: Interdecadal change in sea surface temperature anomalies associated with winter rainfall over south China. J. Geophys. Res., 116, D11101, https://doi.org/ 10.1029/2010JD015425.

— and R. G. Wu, 2010: Respective impacts of the East Asian winter monsoon and ENSO on winter rainfall in China. J. Geophys. Res., 115, D02107, https://doi.org/10.1029/2009JD012502.

$\longrightarrow$, and -2015 : Interdecadal variability of winter precipitation in northwest China and its association with the North Atlantic SST change. Int. J. Climatol., 35, 1172-1179, https:// doi.org/10.1002/joc.4047.

, C. Y. Tam, W. Zhou, and J. C. L. Chan, 2010: Influence of South China Sea SST and the ENSO on winter rainfall over south China. Adv. Atmos. Sci., 27, 832-844, https://doi.org/ 10.1007/s00376-009-9102-7. 